\title{
Inversión pública en el desarrollo del Capital Mental \\ Primera Medición
}

Análisis del caso de la Provincia de Buenos Aires (2013 - 2016)

Máximo Croce

Tesis de Maestría

Maestría en Finanzas Públicas Provinciales y Municipales

Universidad Nacional de La Plata

Director de Tesis: Gustavo Sibilla

2019 


\section{Índice}

Introducción

pág. 2

El origen del concepto de capital mental

pág. 3

El capital mental en las diferentes etapas de la vida

pág. 4

Primera infancia

pág. 4

Infancia

pág. 6

Adolescencia

pág. 7

Adultez

pág. 8

Adultos mayores

pág. 9

Fundamentos económicos del capital mental

pág. 10

Análisis del caso de la Provincia de Buenos Aires (2013-2016)

pág. 12

Metodología de determinación del gasto en capital mental

pág. 12

Magnitud y composición

pág. 15

Capital mental por alcance del impacto

pág. 20

Capital mental por área de impacto

pág. 23

Conclusiones

pág. 27

Referencias

pág. 30

Anexo

Pág. 34

\section{Palabras claves:}

Inversión pública; políticas sociales; capital mental; presupuesto público. 


\section{Introducción}

Partiendo de un concepto innovador de gasto social definido como capital mental, se intentará realizar la primera medición del gasto en inversión en capital mental, en este caso para la Provincia de Buenos Aires, durante el período comprendido entre 2013 y 2016. El gasto en inversión en capital mental es un concepto nuevo que surgió en Inglaterra en 2008, y se lo define como la totalidad de recursos cognitivos, emocionales y sociales con los que una persona cuenta para desenvolverse en la sociedad, adaptarse al entorno e interactuar con los demás y con el medio ambiente. Este conjunto de recursos incluye habilidades cognitivas (la atención, la memoria y el lenguaje), emocionales y sociales (la capacidad para reconocer y controlar las emociones, la empatía, las estrategias de afrontamiento), la capacidad de aprendizaje de manera flexible y eficiente y la resiliencia frente a situaciones de estrés, entre otros.

Como el capital mental representa una constelación amplia de recursos que las personas pueden desarrollar durante toda su vida, el cuidado del mismo excede naturalmente el área de competencia de una jurisdicción determinada. De allí, la importancia de garantizar un enfoque intra e intergubernamental que conecte no sólo a los distintos ministerios entre sí, sino también a los gobiernos locales, organismos internacionales y organizaciones de la sociedad civil.

Dos ejemplos ilustran la importancia de articular actores e intereses para adoptar y escalar hallazgos científicos que impactan directamente sobre el capital mental.

En educación, la intervención temprana está asociada a menores niveles de participación en actos de violencia futuros, mejoras en la productividad laboral, mayores ingresos económicos, menor tolerancia a la corrupción, menor mortalidad materno-infantil y mayor equidad de género, entre otros. La amplitud y profundidad del impacto de las intervenciones educativas necesariamente supera la capacidad y alcance de un Ministerio o dependencia pública equivalente.

De manera similar, en materia de salud la Organización Mundial de la Salud (OMS) sostuvo en 1948 que "la salud es un estado de completo bienestar físico, mental y social, y 
no solamente la ausencia de afecciones o enfermedades”. Más recientemente, la caracterizó como el emergente de una serie de factores que interactúan entre sí y cuyo desbalance o incumplimiento genera malestar o enfermedad. Estos componentes incluyen el estado de adaptación al medio (biológico y sociocultural), el estado fisiológico de equilibrio, el equilibrio entre la forma y la función del organismo (alimentación), y la perspectiva biológica y social (relaciones familiares, hábitos). Por ello, al sostener que "la salud es parte de la responsabilidad de los gobiernos", la OMS interpela a un amplio conjunto de actores estatales y de la sociedad civil por fuera de lo estrictamente sanitario.

Ambas temáticas -la educación y la salud- ilustran por qué el diseño de políticas basadas en evidencia requerirá cambios significativos en la naturaleza compartimentada de la administración pública y la gestión de gobierno.

En los últimos años, esta conceptualización transversal del desarrollo humano se materializó en la visión trazada en los 17 Objetivos de Desarrollo Sostenible (ODS) de la Organización de Naciones Unidas (ONU), entre los que se encuentran terminar con el hambre y la pobreza en todas sus formas, garantizar la seguridad alimentaria y una nutrición mejorada, promover la salud y el bienestar mental y garantizar el acceso a educación de calidad y a la educación superior.

Al ratificar su adhesión a la Agenda 2030, el Estado Argentino se comprometió a abordar aspectos cruciales para el desarrollo del capital mental en materia de educación, vivienda, seguridad alimentaria, provisión de servicios básicos, desarrollo urbano, protección social y gestión del riesgo. Esta agenda de cambio interpela a las 23 provincias y a la Ciudad Autónoma de Buenos Aires (CABA), ya que sus intervenciones tienen un impacto directo sobre la calidad de vida de la ciudadanía y su participación activa resulta imprescindible para alcanzar las 169 Metas propuestas para el año 2030.

En el ámbito científico, la investigación transdisciplinaria será fundamental para determinar cuáles son las condiciones óptimas para el desarrollo de habilidades cognitivas y socioemocionales. 


\section{Desarrollo}

\section{El origen del concepto Capital Mental}

En 2008 la Oficina Gubernamental de Ciencia del Reino Unido desarrolló el proyecto "Capital mental y bienestar: sacando lo mejor de nosotros en el siglo XXI", en el cual se examinan los factores que influyen en el desarrollo mental y el bienestar de una persona a lo largo de su vida.

Dicho informe incorporó los hallazgos resultantes de 85 revisiones científicas y contribuciones de 400 científicos internacionales. El mismo fue desarrollado en torno a dos objetivos: comprender la evidencia disponible e identificar posibles caminos a seguir desde las políticas públicas. Las tres áreas específicas de interés fueron: desarrollo infantil, salud mental y bienestar en el trabajo, y el máximo aprovechamiento de los recursos cognitivos en la tercera edad.

En él se analiza cómo las políticas públicas, los actores relevantes (educadores, profesionales de la salud y empleadores) y los diversos ambientes en los que vivimos (familia, comunidades y nuestro entorno físico) impactan directamente sobre el desarrollo cognitivo y socioemocional. A su vez, se analizan posibles intervenciones para enfrentar retos futuros, basándose en criterios tales como la eficacia científica, los costos, la gobernabilidad, la equidad y la ética.

\section{$\underline{\text { El Capital Mental en las diferentes etapas de la vida }}$}

Pueden señalarse diferentes etapas en la vida de una persona: primera infancia, infancia, adolescencia, adultez y madurez. Donde en cada una de ellas se presentan características y necesidades propias y específicas de cada ciclo.

\section{Primera Infancia: desde la concepción a los 5 años}

La comunidad científica ha alcanzado un consenso en establecer que las intervenciones para promover un óptimo desarrollo humano deben comenzar lo antes posible, ya que el desarrollo cognitivo comienza en el vientre materno. Los primeros 1000 
días de vida, que comprenden desde el momento de la concepción hasta los dos años, proporcionan una importante ventana de oportunidad para cimentar el desarrollo de un niño a lo largo de su vida. Durante este período, el correcto desarrollo de muchos órganos, incluido el cerebro, están condicionados por una adecuada ingesta de nutrientes.

La mayor parte de los problemas nutricionales más prevalentes en nuestro país tienen sus orígenes en esta etapa, y las intervenciones en esta etapa tienen un alto impacto en el capital humano. El retraso en el crecimiento en etapas tempranas se ha asociado con consecuencias que ponen en peligro la equidad en todo el ciclo de vida, incluyendo retraso al ingreso escolar, la conclusión de la escuela y el bajo rendimiento escolar, lo cual reduce la capacidad de trabajo y el capital humano, con un elevado impacto a nivel social.

Además de trastornos del crecimiento, el sobrepeso y la obesidad se han convertido en problemas que afectan a los niños en todo el mundo, especialmente en los países de bajos y medianos ingresos, donde el sobrepeso y la obesidad infantil han aumentado desde el 4,2\% en 1990 al 6,7\% en 2010 (lo que representa más de 35 millones de niños), con un aumento previsto al 9,1\% en 2020. Consecuencias en la salud en el corto y largo plazo.

El éxito de las intervenciones está relacionado a que el estado nutricional se ve afectado por factores que se extienden desde las condiciones sociales, como la reducción de la pobreza y el empoderamiento de las mujeres, a las consideraciones del hogar, tales como la organización de las comidas y la interacciones de la familia en torno a la alimentación.

Además del aspecto nutricional, resulta crucial abordar aspectos como el estrés materno o el consumo de sustancias ya que ambos acarrean riesgos que incluyen el parto prematuro, bajo peso al nacer y problemas de aprendizaje en los niños.

El Instituto Interamericano para el Desarrollo Económico y Social del BID en su trabajo de investigación "La Realidad Social", sostiene que "la mala salud en la primera infancia, medida por el bajo peso al nacer y el estado nutricional, está asociada con un desarrollo cognitivo más deficiente y resultados escolares negativos a largo plazo. Cuando no se satisfacen las necesidades de salud, nutricionales y emocionales de los niños, su desarrollo se detiene. Por consiguiente, vivir en situación de pobreza puede tener efectos nocivos sobre su desarrollo físico y emocional, al igual que sobre las capacidades cognitivas y logros educativos. Lo anterior resulta en serias desventajas para los niños provenientes de familias más vulnerables frente a sus contrapartes de mayores ingresos”. 
Adicionalmente, los programas de intervención para la niñez proporcionan otros valiosos beneficios, entre ellos una mayor igualdad de oportunidades entre hombres y mujeres, mayores tasas de participación laboral femenina, menores tasas de embarazo adolescente no deseado y mejores condiciones de salubridad, en el mediano y largo plazo.

Numerosas investigaciones demuestran que para superar la pobreza, mejorar los resultados educativos e incrementar los niveles de productividad, los gobiernos deben “comenzar por el principio" ofreciendo programas de calidad para la atención prenatal y la educación, servicios integrales de desarrollo de la primera infancia, apoyo y educación para padres, cuidado infantil y educación preescolar, y transiciones efectivas a la escuela primaria.

\section{Infancia: de los 5 a los 10 años}

En este período, los hábitos de vida se ven profundamente modificados por una actividad central: la asistencia a la escuela y la interacción grupal que se establece como un nuevo ámbito que expande los límites del entorno familiar.

En particular, durante esta etapa se consolidan muchos de los hábitos alimentarios y de actividad física así como patrones de conducta importantes para la salud y la prevención de enfermedades crónicas.

La alimentación y la adecuada nutrición en la etapa preescolar y escolar son un factor de relevancia para el correcto crecimiento y desarrollo de los niños. En este sentido, tanto la alimentación ofrecida en hogar como por el programa de alimentación escolar son cruciales. Todos los países del mundo cuentan en la actualidad con programas de alimentación escolar. En los países más desarrollados (USA, Canadá, Unión Europea), los programas tienen una mayor cobertura y estructuración porque aspiran a igualar las oportunidades de todos los niños en la escuela enfatizando el papel sinérgico que desempeñan con el aprendizaje.

Los problemas más comunes en la infancia son los trastornos de desarrollo, aprendizaje y comportamiento. Dichos trastornos pueden ser abordados tempranamente para mitigar su impacto en la vida adulta y reducir el peso futuro sobre los sistemas de salud y servicios sociales. 
Jack Heckman, ganador del premio Nobel en economía en el 2000, asegura que la inversión en el desarrollo durante la primera infancia reduce déficits y fortalece la economía, siendo el momento en que el cerebro vive un mayor número de transformaciones, construyendo las bases para las habilidades cognitivas, motoras y conductuales que habilitan para el éxito en la escuela, la profesión y la vida en general.

Existe consenso en la literatura científica que demuestra que la inversión en salud infantil está asociada a una vida adulta con un mayor número de habilidades socioemocionales y mayores niveles de productividad. Por lo tanto, empoderar a las familias y las comunidades para que puedan proveer de un entorno saludable para el crecimiento de sus hijos debe ser una prioridad. La vida en familia, los jardines maternales y los centros de salud de calidad son cruciales, ya que aportan el contexto apropiado para el desarrollo de habilidades físicas y motoras, de aprendizaje, de lenguaje y habilidades sociales y emocionales.

\section{Adolescencia: de 10 a 19 años}

Asumir un enfoque integral requiere incorporar aspectos emocionales, de violencia, adaptación social, exclusión y discriminación que hoy inciden significativamente en la salud de la población adolescente y juvenil. Prevención y atención, sumadas a la necesaria ampliación en la cobertura y acceso a los servicios de salud, son prerrequisito de una buena política pública para los adolescentes.

En la Argentina, la Encuesta Permanente de Hogares (EPH) evidencia que más de tres cuartos de esta población está constituida por mujeres jóvenes que en numerosas oportunidades no acceden a las opciones de cuidado que les permitirían considerar la compleción educativa o la inserción laboral como alternativas viables.

La incorporación al debate público desde una óptica que privilegia únicamente el foco en lo laboral y lo educativo ha tendido a opacar la complejidad de "las juventudes" en la Argentina, y afecta la posibilidad de explorar los factores multidimensionales que están llevando a amplios sectores de esta población a condicionar su futuro.

Se estima que alrededor del mundo, entre un 10 y $20 \%$ de los adolescentes padecen de patologías de origen neurológico, las cuales representan la principal causa de discapacidad en jóvenes en todas las regiones. Sin embargo, el abordaje a tiempo de los 
trastornos y patologías puede tener un impacto positivo en el desarrollo, el desempeño académico y la posibilidad de llevar adelante una vida productiva.

\section{Adultez: de 19 a 65 años}

Durante la adultez, los individuos despliegan sus recursos cognitivos y socioemocionales en diversos ámbitos. Sin embargo, los trastornos mentales y neurológicos aumentan a nivel global, afectando la salud de las personas y ocasionando graves consecuencias a nivel socioeconómico.

Aquí el trabajo es uno de los grandes ordenadores en la vida de las personas, de la seguridad, de la familia y de la cultura en general. La falta de empleo, además de sus consecuencias económicas en el plano individual y social, puede repercutir en diversas afecciones socioemocionales, sumado al posible padecimiento del estigma social.

Por su parte, el estrés laboral, el consumo excesivo de alcohol y drogas, y la violencia (tanto física como psicológica), dan lugar a problemas de salud así como a menores tasas de productividad. En conjunto representan una de las principales causas de accidentes, lesiones, enfermedades y ausentismo en el trabajo, tanto en los países desarrollados como en los países en desarrollo.

La Organización Internacional del Trabajo (OIT) estima que las pérdidas debidas a indemnizaciones, días de trabajo perdidos, interrupciones de la producción, formación profesional y gastos médicos, entre otros, representan el $4 \%$ del producto interno bruto mundial. Para la prevención y abordaje de la violencia en el trabajo y la promoción de la salud laboral, la OIT utiliza el enfoque del diálogo social con el fin de promover la ejecución de iniciativas exitosas en el lugar de trabajo y en la comunidad, la cual incluye la participación activa de los empleadores, los trabajadores, los gobiernos, los servicios públicos y las ONG.

Las intervenciones en política pública durante esta etapa vital, deben enfocarse en reducir el desempleo o empleo precario, promover la salud laboral y desarrollar la reserva cognitiva y la resiliencia para la sociedad adulta en general. El concepto "reserva cognitiva" hace referencia a los recursos de una persona que la protegen contra el deterioro cognitivo, como la disminución o el déficit de la memoria y la atención, que pueden impactar en tareas de aprendizaje o laborales. 


\section{Adultos Mayores: de 65 años en adelante}

El envejecimiento de la población es uno de los fenómenos demográficos más importantes de nuestra época. La CEPAL advierte que el nivel de envejecimiento que los países europeos lograron en 2 siglos, lo alcanzará América Latina y el Caribe en apenas 50 años -provocado por las variaciones en las tasas de fecundidad y mortalidad- y en condiciones económicas menos favorables. A nivel mundial, el año 2050 es tomado como un hito temporal de relevancia para analizar el envejecimiento poblacional. En esa fecha por primera vez la población mayor de 60 años sobrepasará a los niños y jóvenes.

Por ende, con este crecimiento acelerado de la población adulta mayor, el desafío será brindar un servicio de salud que garantice, no sólo que las personas vivan por más tiempo, sino que vivan mejor. Es decir, que puedan satisfacer las demandas que las tendencias demográficas anticipan.

Por otra parte, resulta primordial educar a la población en la importancia del cuidado de la alimentación, el ejercicio físico, el entrenamiento cognitivo, el cuidado de los afectos y la importancia de evitar los excesos (tabaco, alcohol, drogas) como factores protectores para el funcionamiento óptimo de la salud física y mental. Por ello, las intervenciones que se dirijan a prevenir el deterioro cognitivo y psicoafectivo de los adultos mayores cobrarán una relevancia aún mayor, así como todos los programa que promuevan los factores protectores que favorecen a la reserva cognitiva y al desarrollo de las habilidades sociales y emocionales.

En el mismo sentido, a medida que las personas alcanzan una edad avanzada, el aprendizaje debe continuar siendo promovido y fomentado, ya que esto ayuda a proteger contra el deterioro cognitivo.

Además, debe estimularse la formación permanente, tanto en los trabajadores como en los empleadores, aumentando la concientización y proporcionando incentivos. Las nuevas tecnologías también están disponibles y se están desarrollando constantemente para personalizar el aprendizaje. A medida que las personas alcanzan una edad avanzada, el aprendizaje debe continuar siendo promovido y fomentado, ya que esto puede proteger contra el deterioro cognitivo. En particular, la tecnología de la información tiene un papel importante en ayudar a las personas a superar los efectos negativos sobre la memoria. 


\section{Fundamentos Económicos del Capital Mental}

En torno al crecimiento económico, que ha sido uno de los puntos más controversiales en la teoría económica a lo largo de la literatura, y con el riesgo de ser profundamente simplista, pueden enunciarse dos grandes teorías que, hoy en día, intentan explicarlo bajo diferentes perspectivas: la Marginalista y la Clásica.

Bajo la Teoría Marginalista, el crecimiento está liderado por la tasa de progreso técnico o la tasa de ahorro. Fue Robert Solow (1956) quien intentó estimar las fuentes del crecimiento económico, hallando resultados sorprendentes: cerca del $88 \%$ del crecimiento era explicado por los residuos. En otras palabras, no podía ser explicado por los factores productivos tradicionales, como la tierra, el trabajo y el capital físico.

Más tarde, derivado de las Controversias del Capital de Cambridge, donde la definición y la forma de medir el capital fueron sometidas a debate (Lazzarini, 2011), una teoría económica alternativa basada en la Teoría Clásica empezó a consolidarse. Como los autores clásicos no tenían una teoría del producto (Mongiovi, 1990) derivado de la creencia en la Ley de Say, sumado a la dificultad de compatibilizar el componente de la inversión como oferta y demanda simultánea, los modelos de crecimiento liderados por la demanda tardaron en aparecer. Fue a partir del modelo del supermultiplicador Sraffiano, desarrollado por Franklin Serrano (1995), que la Teoría Clásica se constituyó en una alternativa real a la teoría mainstream. Bajo este marco, los componentes autónomos de la demanda agregada, entre los que se encuentran el Gasto Público, son los que marcarían el sendero de crecimiento de una economía, permitiendo que éste sea liderado por la demanda, y no, como en la teoría tradicional, por la oferta.

El capital humano $(\mathrm{CH})$ surgió, en la Teoría Marginalista, como una respuesta al indescifrable enigma del residuo de Solow, dado que tal vez el conocimiento y las capacidades de los trabajadores podrían explicar una parte del crecimiento, la acumulación de capital también se daría en la fuerza de trabajo. Es así como una vertiente en la explicación cualitativa de los factores surgió a partir de este desarrollo incipiente. Luego, las teorías del CH, desarrolladas principalmente por Schultz (1961) y Becker (1962), por lo general fueron basadas en el nivel educativo de los individuos, lo que era una manera fácil de medir y trasladarlo a los costos. Más tarde, también se incorporaron temas de salud. Pero 
a partir de esta noción, las teorías de crecimiento endógeno desplegaron todo su potencial. Ya no sería necesaria la tecnología para explicar el crecimiento; es así como surgieron los modelos que incorporaban el $\mathrm{CH}$ en la función de producción agregada.

En la Teoría Clásica, con respecto al crecimiento económico, una de las ventajas de la inversión pública en capital mental es que puede llegar a ser un vector de crecimiento de la economía. Bajo este marco, las partidas de inversión pública asociadas a este componente autónomo de la demanda agregada podrían generar la demanda suficiente para que la capacidad productiva, por el lado de la oferta, se expanda; revirtiendo la famosa Ley de Say (Serrano, 1995).

Algunos autores señalan que las nuevas teorías del crecimiento -en este caso, el modelo de Dissou et. al (2016)- implican un retorno a los modos de pensamiento y el método de análisis característicos de los autores clásicos (Kurz \& Salvadori, 2003), por lo que se debe reconsiderar una posible convergencia entre ambos enfoques.

Uno de los teóricos Clásicos que suele estar relacionado a ambas teorías es Adam Smith. Este autor sostiene en su libro "Una investigación sobre la naturaleza y causas de la riqueza de las naciones" (1776) que "una persona que se ha educado con la inversión de mucho tiempo y trabajo en cualquier ocupación que requiere una destreza y habilidad extraordinarias puede ser comparada con una de esas costosas máquinas."

Con esta frase, Adam Smith sentó las bases para la incorporación del enfoque del Capital Humano en la teoría neoclásica y, en este sentido, planteó primigeniamente la posibilidad del crecimiento a partir de las nociones de división del trabajo, especialización y maquinización a medida que se expande el mercado. Así su influencia en ambos enfoques es suficiente como para que, bajo perspectivas completamente diferentes se pueda llegar a conclusiones muy similares en cuanto a decisiones de política económica, donde la inversión pública dirigida a capital mental podría ser una herramienta más en pos de mejorar el bienestar de los habitantes, incluso bajo cualquier forma de financiación. 


\title{
Análisis del caso de la Provincia de Buenos Aires
}

\author{
Metodología de determinación del Gasto en Inversión en Capital Mental
}

Para la determinación del gasto en inversión de capital mental (GCM) elaboré la primer metodología que se nutrió de esfuerzos previos para la medición del Gasto Público Social (GPS), Gasto en Niñez y Adolescencia, y en Adultos Mayores, llevados a cabo por varios gobiernos, organismos internacionales y tratados por una creciente producción académica. Entre uno de los últimos estudios para nuestro país se encuentra el "Gasto Social de la Administración Pública Nacional dirigido a la Niñez en Argentina" UNICEFASAP (2015). ${ }^{1}$

La determinación cuantitativa del GCM fue instrumentada de acuerdo con los siguientes pasos:

\section{Delimitación del universo institucional}

Se estableció que el universo contemplado correspondía a la Administración Pública Provincial (APP) de la Provincia de Buenos Aires (PBA) entre los años 2013 y $2016 .{ }^{2}$

2. Relevamiento de la estructura programática provincial

Se compiló la totalidad de programas presupuestarios de la provincia en el periodo, se repasaron las definiciones de sus objetivos y se desagregaron los tipos de gasto.

\section{Clasificación según áreas de impacto}

Se clasificó cada programa en función del área de bienestar y eje de intervención a que contribuye:

a. Alimentación saludable: comprende programas que se enfoquen en lactancia materna, alimentación temprana, programas alimentarios, monitoreo del estado alimentario

\footnotetext{
${ }^{1}$ Para una revisión exhaustiva de la bibliografía especializada en la materia ver: Bonari, Damián (2015), "Gasto-Inversión en protección Social. Medición de gasto e inversión en Juventud", Santiago de Chile, CEPAL.

2 La Administración Pública Provincial (APP) incluye a la Administración Central, los organismos descentralizados y las instituciones de seguridad social. No se incluye el gasto de las empresas y sociedades del Estado, las obras sociales, los fondos fiduciarios y todos los entes autárquicos que desarrollen actividades empresariales.
} 
nutricional, promoción de alimentación saludable, entre otros aspectos relativos a la situación alimentaria nutricional de la población.

b. Entorno saludable y estímulo cognitivo: comprende programas que se enfoquen en estimulación cognitiva, motivación, inspiración, esfuerzo, superación de esquemas mentales, aprendizaje a lo largo de la vida, prevención de adicciones, promoción de la salud mental, actividad física, deportes, juego, actividades recreativas, actividades que promuevan el bienestar, actividades que reduzcan el estrés, entre otras.

c. Educación de calidad: comprende iniciativas que se enfoquen en estimulación cognitiva en la primera infancia, motivación para el aprendizaje, estímulo para acceder y culminar la educación secundaria y superior, actividad física, incorporación/reincorporación de personas al sistema educativo, ampliación del acceso a la educación, disminución de la deserción escolar, capacitación en materia específica (matemática, lengua, ciencias sociales, oficios), mejora de la lectocomprensión, aumento de la motivación, mejora de la relación con pares y superiores, herramientas (TICs) que mejoren el aprendizaje, infraestructura educativa, entre otras.

d. Estímulo socioemocional: comprende iniciativas que se enfoquen en el desarrollo de habilidades sociales, la interacción padres-hijos, los vínculos intergeneracionales, la prevención de la violencia, los vínculos con la comunidad, actividades recreativas (juego, meditación, hobbies, actividades al aire libre), actividades relacionadas con las artes, entre otras.

\section{Clasificación según alcance}

Se clasificó cada programa en función de la naturaleza de sus destinatarios. El alcance del programa determina si el tipo de impacto sobre la población es directo o indirecto. Se entiende que todo programa o proyecto que está dirigido a la población objetivo o grupo biológico específico, impactará de forma directa sobre su Capital Mental. Mientras que, si la iniciativa se destina a instituciones, mediadores, bienes públicos o gestión de políticas públicas, su impacto será considerado indirecto. Entre las posibilidades identificadas para el alcance se encuentran:

- Población objetivo: programa o proyecto destinado a población materno-infantil, niños, adolescentes y/o adultos mayores. 
- Institución: programa o proyecto desarrollado en escuelas, museos, universidades, organismos de gobierno.

- $\quad$ Mediadores: programa o proyecto destinado a docentes, directivos, familiares de la población objetivo, capacitadores, cuidadores, empleados públicos, investigadores, administradores de instituciones educativas, líderes académicos, personal de apoyo, personal de bibliotecas, informática, finanzas, entre otros.

- Bien público: programa o proyecto destinado a mejorar la infraestructura de escuelas, hospitales, instituciones, mejorar la vía pública, redes cloacales, red de agua potable, iluminación, entre otros.

- $\quad$ Política pública: programa o proyecto para estímulo a actividades, observatorios de derechos, coordinación de programas, planificación, gestión, administración.

\section{Prorrateo según grupo etario}

Se prorrateó, gracias a la colaboración de la Dirección Provincial de Estudios Económicos del Ministerio de Economía de la PBA, cada uno de los programas en función del grupo etario de sus destinatarios: 1. Primera Infancia; 2. Niñez; 3. Adultos; y 4. Adultos Mayores.

\section{Elaboración de matrices}

Se confeccionaron tablas por año, áreas de impacto, alcance y grupo etario.

A continuación se presenta una tabla donde podrá observarse a modo de resumen la metodología aplicada:

\begin{tabular}{|c|c|c|c|c|}
\hline $\begin{array}{l}1 \text { - Identificar programa } \\
\text { gubernamental }\end{array}$ & $\begin{array}{l}2 \text { - Identificar área o áreas de } \\
\text { impacto espe cífico }\end{array}$ & $\begin{array}{c}\text { 3- Establecer alcance del } \\
\text { programa }\end{array}$ & $\begin{array}{l}\text { 4- El alcance de termina el tipo } \\
\text { de impacto en CM }\end{array}$ & $\begin{array}{l}5 \text { - El programa contribuye a } \\
\text { preservar y/o desarrollar el CM }\end{array}$ \\
\hline \multirow{10}{*}{ PROGRAMA } & & a- Población objetivo & IMPACTO DIRECTO & SI \\
\hline & 1- alimentación saludable & & & \\
\hline & 2- entorno saludable y estímulo cognitivo & & & \\
\hline & 3- educación de calidad & & & \\
\hline & 4- estímulo socioemocional & & & \\
\hline & & b - Institución & IMPACTO INDIRECTO & SI \\
\hline & & c-Mediadores & IMPACTO INDIRECTO & SI \\
\hline & & d - Bien público & IMPACTO INDIRECTO & SI \\
\hline & & e-Política pública & IMPACTO INDIRECTO & SI \\
\hline & 5- otras áreas & No relevante & SIN IMPACTO EN CM & No \\
\hline
\end{tabular}




\section{Ejemplo de aplicación de la metodología}

1. Programa: Servicio Alimentario Escolar

2. Descripción del programa: El Servicio Alimentario Escolar (SAE) está dirigido a niños y adolescentes en situación de vulnerabilidad social, escolarizados en escuelas públicas de la Provincia, con el objetivo de garantizar una cobertura nutricional uniforme asistiendo particularmente a los más vulnerables.

3. Área de impacto: alimentación saludable.

4. Alcance: niños y adolescentes.

5. Tipo de impacto: Directo.

\section{Magnitud y composición}

Tras el relevamiento de las estructuras programáticas de la Administración Pública Provincial, y la posterior clasificación de los programas en función de sus áreas de impacto y alcance, se arribó a la construcción de una matriz consolidada cuyos principales rasgos se detallan en los cuadros a continuación.

\section{Gasto en Capital Mental}

En millones de pesos corrientes

\begin{tabular}{|c|c|c|c|c|c|c|}
\hline \multicolumn{3}{|c|}{ Concepto } & 2013 & 2014 & 2015 & 2016 \\
\hline \multirow{5}{*}{$\begin{array}{c}\text { Gasto en } \\
\text { Capital } \\
\text { mental }\end{array}$} & \multirow{3}{*}{ Niñez } & Primera infancia & $\$ 10.229$ & $\$ 12.606$ & $\$ 21.866$ & $\$ 24.879$ \\
\hline & & Niñez y adolescencia & $\$ 33.265$ & $\$ 40.933$ & $\$ 59.131$ & $\$ 76.289$ \\
\hline & & Subtotal & $\$ 43.494$ & $\$ 53.539$ & $\$ 80.998$ & $\$ 101.168$ \\
\hline & \multicolumn{2}{|c|}{ Adultos } & $\$ 12.742$ & $\$ 19.327$ & $\$ 31.691$ & $\$ 42.201$ \\
\hline & \multicolumn{2}{|c|}{ Adultos mayores } & \$ 3.269 & $\$ 4.039$ & $\$ 5.728$ & \$ 8.644 \\
\hline
\end{tabular}

Fuente: Elaboración propia en base a datos del Min. Economía PBA.

El GCM alcanzó en 2016 un valor de \$152.013 millones, experimentando un incremento de $\$ 33.597$ millones respecto a 2015 (+ 28,4\%). El comportamiento de la 
variable ha sido nominalmente positivo a lo largo de toda la serie, con un crecimiento interanual promedio de $37,2 \% .^{3}$

A efectos de determinar el esfuerzo en desarrollo del capital mental por grupo etario se utilizó la matriz de beneficiarios por programa elaborada por la Dirección Provincial de Estudios Económicos (DPEE) del Ministerio de Economía de PBA, permitiendo aplicar indicadores de prorrateo para cada uno de los programas en el período de análisis tratado.

En 2016, la distribución del GCM por grupo etario arrojó que dos tercios eran destinados a la niñez $(66,6 \%)$, un cuarto a adultos $(27,7 \%)$ y un $5,7 \%$ a adultos mayores. Lo que implicó \$101.168 millones para el primer grupo etario, \$42.201 millones para el segundo y \$8.644 millones para los adultos mayores. Siendo el último el que más creció en término relativos su participación el último año, de 5.728 millones de pesos en 2015 a \$8.644 millones en 2016, variación interanual de 50,9\%.

En el siguiente gráfico puede observarse la evolución anual de los recursos destinados a cada grupo etario, comprendiendo en primera infancia, niñez y adolescencia, adultos y adultos mayores.

\section{Gasto en Capital Mental por grupo etario}

En millones de pesos corrientes

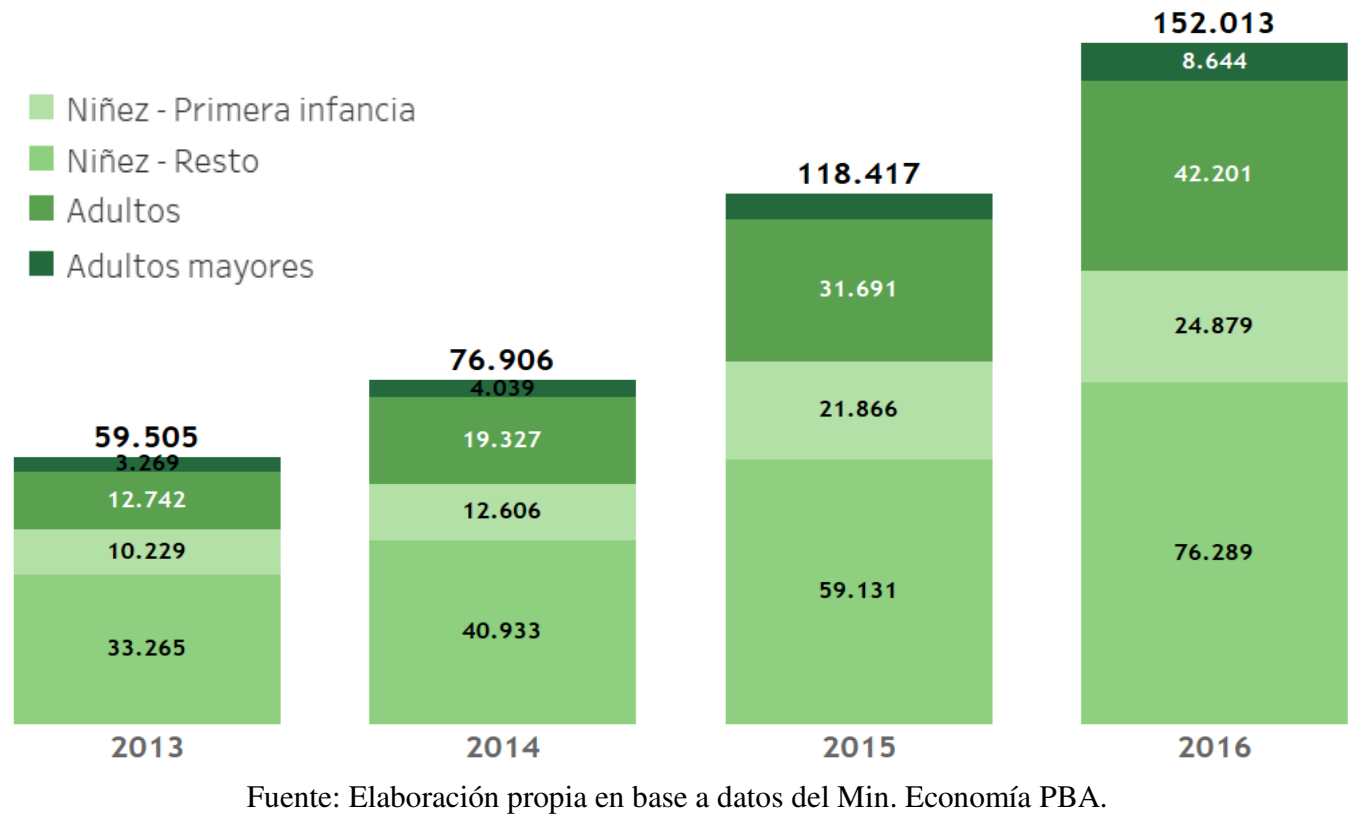

\footnotetext{
${ }^{3}$ Debido a la ausencia de índices de precios gubernamentales resulta impreciso deflactar gastos corrientes para obtener series en moneda constante. Por ello, en este estudio se limitará la observación a valores corrientes de cada año.
} 
Como se observa el GCM tuvo un crecimiento nominal ininterrumpido, con énfasis constante en el grupo etario de niños y adolescentes que alcanzó una participación por encima del $66 \%$ durante toda la serie.

\section{Gasto en Capital Mental per cápita}

En pesos corrientes

\begin{tabular}{|l|l|l|l|l|l|}
\hline & Concepto & 2013 & 2014 & 2015 & 2016 \\
\hline \multirow{2}{*}{$\begin{array}{c}\text { Gasto en niño (Primera Infancia) } \\
\begin{array}{c}\text { Capital } \\
\text { Mental }\end{array}\end{array}$} & $\$ 6.318$ & $\$ 7.699$ & $\$ 13.207$ & $\$ 14.865$ \\
\hline & Por niño (niñez y adolescencia) & $\$ 9.034$ & $\$ 10.995$ & $\$ 16.450$ & $\$ 20.326$ \\
\hline & Por adulto mayor & $\$ 5.287$ & $\$ 7.928$ & $\$ 12.856$ & $\$ 16.936$ \\
\hline
\end{tabular}

Fuente: Elaboración propia en base a datos del Min. Economía PBA.

El examen del GCM es susceptible de un abordaje alternativo a partir del cálculo del gasto medio por grupo etario. Para ello se dimensionó el universo total de niños, adultos y adultos mayores tomando como referencias estadísticas el Censo Nacional 2010, datos de la Encuesta Permanente de Hogares (EPH), la base de datos de la DPEE y otras fuentes oficiales. De esta manera, pudo despejarse el GCM per cápita:

\section{Gasto en Capital Mental per cápita 2013 - 2016}

En pesos corrientes

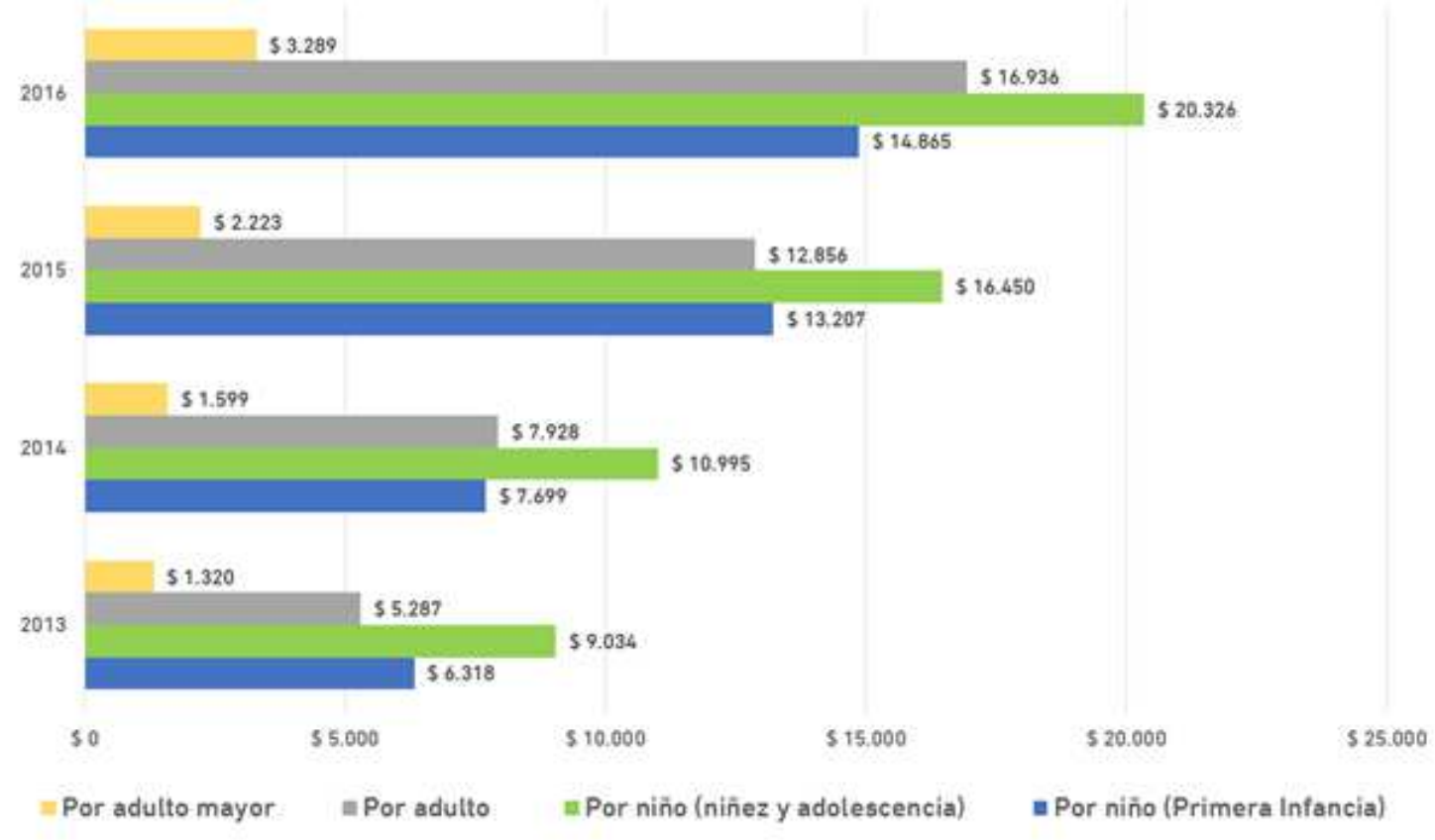

Fuente: Elaboración propia en base a datos del Min. Economía PBA.

Como se desprende del siguiente cuadro, en 2016 el gobierno provincial invirtió $\$ 20.326$ en el capital mental de cada niño bonaerense, $\$ 16.936$ por adulto bonaerense y 
$\$ 3.289$ por adulto mayor bonaerense. Lo que implica un incremento de $\$ 3.876$ por cada niño, $\$ 4.080$ por adulto y $\$ 1.066$ por adulto mayor, con respecto al año anterior.

Se evidencia así un patrón uniforme en la tendencia menguante del gasto con el avance de la vida, siendo el mayor gasto al comienzo del ciclo de vida de las personas, en concordancia con la ventaja de la intervención temprana y la teoría económica.

Asumiendo que el capital mental constituye un factor central de la productividad de una economía, es relevante el análisis del nivel de la riqueza actual generada que se reinvierte para obtener mayor rendimiento a futuro.

En este sentido, los cálculos arrojan que en promedio se invirtió un 6,5\% del PBG entre 2013 y 2016. En 2016 el Estado provincial invirtió un 6,8 \% del Producto Bruto Geográfico (PBG), frente a 7,2\% en 2015, 6\% en 2014 y 6,1\% en $2013 .{ }^{4}$

\section{Gasto en Capital Mental}

En \% PBG

\begin{tabular}{|c|c|c|c|c|c|c|}
\hline \multicolumn{3}{|c|}{ Concepto } & 2013 & 2014 & 2015 & 2016 \\
\hline \multirow{5}{*}{$\begin{array}{l}\text { Gasto en } \\
\text { Capital } \\
\text { mental }\end{array}$} & \multirow{3}{*}{ Niñez } & Primera infancia & $1,0 \%$ & $1,0 \%$ & $1,3 \%$ & $1,1 \%$ \\
\hline & & Niñez y adolescencia & $3,4 \%$ & $3,2 \%$ & $3,6 \%$ & $3,4 \%$ \\
\hline & & Subtotal & $4,4 \%$ & $4,2 \%$ & $5,0 \%$ & $4,5 \%$ \\
\hline & \multicolumn{2}{|c|}{ Adultos } & $1,3 \%$ & $1,5 \%$ & $1,9 \%$ & $1,9 \%$ \\
\hline & \multicolumn{2}{|c|}{ Adultos mayores } & $0,3 \%$ & $0,3 \%$ & $0,4 \%$ & $0,4 \%$ \\
\hline & \multicolumn{2}{|c|}{ TOTAL } & $6,1 \%$ & $6,0 \%$ & $7,2 \%$ & $6,8 \%$ \\
\hline
\end{tabular}

Fuente: Elaboración propia en base a datos del Min. Economía PBA.

En el siguiente gráfico se vislumbran los ratios por grupo etario en relación con el PBG, pudiendo una vez más destacarse la participación del grupo etario niñez con el 4,5\% del producto de los bonaerenses en 2016. En cuanto al grupo etario de los adultos, la ratio alcanza en 2015 y 2016 un valor de 1,9\% del PBG con una tendencia ascendente respecto al inicio de la serie. Análogo sucede con los adultos mayores que promedia una participación relativa de $0,35 \%$ en los años observados, con un comportamiento en alza.

Otra medida empleada para dimensionar parcialmente la importancia de una función de gobierno es el peso de su asignación dentro del Gasto Público Total (GPT). Esa ratio representa un reflejo inicial del nivel de prioridad financiera dado por las autoridades a la

\footnotetext{
${ }^{4}$ Debido a la emergencia reciente del concepto de Capital Mental se carece de mediciones internacionales para comparar estos guarismos.
} 
temática. ${ }^{5}$ El peso relativo de una categoría evoluciona conforme lo hace su velocidad de cambio respecto al experimentado por el gasto total. Cuando la categoría crece por encima de la media gana participación relativa e inversamente la pierde cuando lo hace por debajo.

\section{Gasto en Capital Mental}

En \% GPT

\begin{tabular}{|c|c|c|c|c|c|c|}
\hline \multicolumn{3}{|c|}{ Concepto } & 2013 & 2014 & 2015 & 2016 \\
\hline \multirow{5}{*}{$\begin{array}{l}\text { Gasto en } \\
\text { Capital } \\
\text { mental }\end{array}$} & \multirow{3}{*}{ Niñez } & Primera infancia & $6,5 \%$ & $5,9 \%$ & $6,9 \%$ & $5,7 \%$ \\
\hline & & Niñez y adolescencia & $21,1 \%$ & $19,1 \%$ & $18,6 \%$ & $17,4 \%$ \\
\hline & & Subtotal & $27,6 \%$ & $25,0 \%$ & $25,5 \%$ & $23,0 \%$ \\
\hline & \multicolumn{2}{|c|}{ Adultos } & $8,1 \%$ & $9,0 \%$ & $10,0 \%$ & $9,6 \%$ \\
\hline & \multicolumn{2}{|c|}{ Adultos mayores } & $2,1 \%$ & $1,9 \%$ & $1,8 \%$ & $2,0 \%$ \\
\hline \multicolumn{3}{|c|}{ TOTAL } & $37,8 \%$ & $35,8 \%$ & $\mathbf{3 7 , 3} \%$ & $34,6 \%$ \\
\hline
\end{tabular}

Fuente: Elaboración propia en base a datos del Min. Economía PBA.

El GCM ha mostrado en la serie bajo estudio una participación promedio de $36,4 \%$ del GPT, con valores superiores en los años pares e inferiores en los impares. En 2016 experimentó una merma en su participación, cayendo a 34,6 \% del GPT desde un registro de $37,3 \%$ en $2015 .^{6}$ De un modo similar se había comportado en 2014 cuando se vio reducir su participación a 35,8\% partiendo de 37,8\% en el año anterior. Cuestión que también sucede para los distintos grupos etarios en los años mencionados.

Otra visión de análisis, como se plasma a continuación, permite considerar al capital mental dimensionado dentro del total de gastos públicos destinados exclusivamente a la finalidad social de los mismos, permitiendo así dimensionar la importancia que presenta para el estado provincial.

Se considera Gasto Público Social (GPS) a todo gasto inherente a la finalidad Servicios Sociales que, según el Clasificador Presupuestario vigente, son aquellas erogaciones destinadas a la prestación de servicios de salud, promoción y asistencia social, seguridad social, educación y cultura, ciencia y técnica, trabajo, vivienda y urbanismo, agua potable y alcantarillado y otros servicios urbanos. Estas categorías constituyen las funciones que se consolidan a partir de la naturaleza de los programas presupuestarios.

\footnotetext{
${ }^{5}$ Debe tenerse presente que el peso relativo del gasto en una función determinada respecto al total del presupuesto es una aproximación parcial a su grado de prioridad. La competencia regulatoria del Estado es otra dimensión que también debe considerarse y que puede tener poca o nula exteriorización presupuestaria.

${ }^{6}$ Una de las razones que explican la caída en 2016 respecto a 2015 es la inclusión en el GPT de un gasto extraordinario del orden de los 12 mil millones de pesos de la Administración Provincial en la Obra Social del BAPRO. Tal devengamiento produce una distorsión notable que resulta parcialmente corregida cuando se mensura el GCM dentro del GPS.
} 


\section{Gasto en Capital Mental}

En \% GPS

\begin{tabular}{|c|c|c|c|c|c|c|}
\hline \multicolumn{3}{|c|}{ Concepto } & 2013 & 2014 & 2015 & 2016 \\
\hline \multirow{5}{*}{$\begin{array}{c}\text { Gasto en } \\
\text { Capital } \\
\text { mental }\end{array}$} & \multirow{3}{*}{ Niñez } & Primera infancia & $10,8 \%$ & $10,2 \%$ & $11,9 \%$ & $10,6 \%$ \\
\hline & & Niñez y adolescencia & $36,2 \%$ & $33,3 \%$ & $32,3 \%$ & $30,6 \%$ \\
\hline & & Subtotal & $47,0 \%$ & $43,5 \%$ & $44,1 \%$ & $41,2 \%$ \\
\hline & \multicolumn{2}{|c|}{ Adultos } & $12,2 \%$ & $13,8 \%$ & $15,2 \%$ & $17,2 \%$ \\
\hline & \multicolumn{2}{|c|}{ Adultos mayores } & $3,4 \%$ & $3,2 \%$ & $3,0 \%$ & $3,5 \%$ \\
\hline & \multicolumn{2}{|c|}{ TOTAL } & $62,6 \%$ & $60,4 \%$ & $62,4 \%$ & $62,0 \%$ \\
\hline
\end{tabular}

Fuente: Elaboración propia en base a datos del Min. Economía PBA.

El GCM presenta una participación en la serie de un 61,8\% del GPS. En 2014 la variable experimentó una caída en su participación, pasando a un valor del 60,4\% desde un registro de 62,6 \% en 2013, volviendo a valores en torno al 62\% para 2015 y 2016.

Los promedios históricos para cada uno de los grupos etarios son de 18,8\% para primera infancia, $33,1 \%$ para niñez y adolescencia, $14,6 \%$ para adultos y 3,2\% para adultos mayores. Donde, para los niños el promedio histórico es de 43,9\% del GPS.

Se revela el peso central que representan los grupos de primera infancia, niñez y adolescencia con un promedio para la serie del 43,9\% del GPS, seguido por 14,6\% para adultos y de 3,2\% para adultos mayores. Proporciones que se mantienen relativamente uniformes para los años de análisis.

\section{$\underline{\text { Capital mental por alcance del impacto }}$}

En esta clasificación se caracteriza el GCM según el alcance de su impacto, directo o indirecto. Como se mencionó, todo programa o proyecto que está dirigido a la población objetivo o grupo biológico específico impacta de forma directa sobre su capital mental. Mientras que si la iniciativa se destina a instituciones, mediadores, bienes públicos o gestión de políticas públicas, su impacto es considerado indirecto.

Bajo esta metodología se observa que en promedio el 68,6\% del GCM es considerado gasto directo, mientras que el 31,4\% restante es indirecto.

\section{Gasto en Capital Mental por alcance del impacto}

En millones de pesos corrientes y porcentaje

\begin{tabular}{|c|c|c|c|c|c|c|c|c|}
\hline \multirow[b]{2}{*}{ Clase } & \multicolumn{2}{|c|}{2013} & \multicolumn{2}{|c|}{2014} & \multicolumn{2}{|c|}{2015} & \multicolumn{2}{|c|}{2016} \\
\hline & $\begin{array}{l}\text { En mm de S } \\
\text { corrientes }\end{array}$ & $\begin{array}{c}\text { En } \\
\text { porcentaje }\end{array}$ & $\begin{array}{l}\text { En mm de } \$ \\
\text { corrientes }\end{array}$ & $\begin{array}{c}\text { En } \\
\text { porcentaje }\end{array}$ & $\begin{array}{l}\text { En mm de } \mathrm{S} \\
\text { corrientes }\end{array}$ & $\begin{array}{c}\text { En } \\
\text { porcentaje }\end{array}$ & $\begin{array}{l}\text { En mm de S } \\
\text { corrientes }\end{array}$ & $\begin{array}{c}\text { En } \\
\text { porcentaje }\end{array}$ \\
\hline Directo & 40.445 & $68,0 \%$ & 51.592 & $67,1 \%$ & 83.361 & $70,4 \%$ & 105.090 & $69,1 \%$ \\
\hline Indirecto & 19.060 & $32,0 \%$ & 25.315 & $32,9 \%$ & 35.057 & $29,6 \%$ & 46.924 & $30,9 \%$ \\
\hline Total & 59.505 & $100 \%$ & 76.907 & $100 \%$ & 118.417 & $100 \%$ & 152.013 & $100 \%$ \\
\hline
\end{tabular}

Fuente: Elaboración propia en base a datos del Min. Economía PBA. 
Del total de GCM para 2016, que fue de $\$ 152.013$ millones, $\$ 105.090$ millones fueron destinados a programas y proyectos que contribuyeron en forma directa al cuidado y desarrollo del capital mental de los bonaerenses, equivalente al 69,1\%; y \$46.924 millones a los que contribuyeron en forma indirecta, el 30,9\%.

Para 2015, el GCM total fue de $\$ 118.417$ millones, donde $\$ 83.361$ millones se destinaron a programas que impactan de manera directa y $\$ 35.057$ millones a los que también impactan al cuidado y desarrollo del capital mental pero de manera indirecta.

En 2016, con respecto al año anterior, se incrementó el monto destinado a los programas y proyectos que impactan directamente en $\$ 21.729$ millones y a los que impactan de forma indirecta en $\$ 11.867$ millones, siendo sus incrementos interanuales de $26 \%$ y $33,8 \%$, respectivamente.

Con respecto a 2014, el monto destinado al capital mental fue de $\$ 76.907$ millones, donde $\$ 51.592$ millones corresponden a los gastos directos y $\$ 25.315$ millones a los indirectos. Siendo sus incrementos con respecto a 2013, de $\$ 11.147$ millones para los primeros y de $\$ 6.255$ millones para los segundos, lo que implica un crecimiento interanual de $27,6 \%$ y $32,8 \%$ respectivamente.

La proporción de recursos destinados a los programas, que contribuyen de manera directa e indirecta al capital mental, se mantiene relativamente estable y centrada en su media a lo largo de estos años. Siendo sus promedios de 68,6\% y de 31,4\%, respectivamente.

En el anexo del presente trabajo se plasma el detalle para cada uno de los grupos etarios, donde, en términos generales se encuentra que los promedios de gastos directos e indirectos para primera infancia son de $63,6 \%$ y 36,4\%; para niñez y adolescencia de $70,3 \%$ y 29,7\%; para adultos de 66,8\% y 33,2\%; y para adultos mayores de $55,1 \%$ y 44,9\%, respectivamente. Evidenciándose, que los gastos focalizados son mayores en los primeros grupos etarios, sobre todo en niñez y adolescencia, y menores en el último.

Recordando la clasificación en función de la naturaleza de sus destinatarios que se utilizó para discriminar si su efecto en el capital mental era de manera directa o indirecta, puede realizarse la apertura de su alcance del programa en población objetivo, institución, mediadores, bien público y política pública. 
Se observa un crecimiento en valores corrientes de todas las áreas de alcance de los programas presupuestarios con excepción de Instituciones, que presentó una merma en 2016 de $\$ 85$ millones $(-15,7 \%)$ con respecto al año anterior, compensada por el incremento del área de Bien Público.

Para 2016, el incremento con respecto a 2015 para las distintas áreas de alcance fue para Población objetivo de \$20.500 millones (+25,8\%); Mediadores de \$5.087 millones $(+25,4 \%)$; Bien público de $\$ 1.013$ millones $(+116,3 \%) ;$ y, Política pública de $\$ 7.083$ millones $(+40,7 \%)$.

Siendo para toda la serie en general y para cada año en particular, el área más predominante la de Población objetivo, seguida por Mediadores y, tercero por Política público. Luego con menor peso se encuentran Bien público e Instituciones.

En términos porcentuales, para 2016, Población objetivo representa el 65,7\%, Mediadores el 16,5\%, Política pública el 16,1\%, Bien público el 1,2\% e Instituciones el $0,35 \%$ del total de gastos en capital mental. Las posiciones de sus participaciones relativas en el gasto total se mantienen, pero se encuentran pequeñas variaciones en sus porcentajes de GCM con respecto a cada año.

En el anexo pueden apreciarse el impacto de cada alcance de los programas para los distintos grupos etarios, y en los gráficos se observa cómo ha evolucionado el gasto para las áreas de alcance en los años de estudio. En resumen, para los grupos etarios se mantienen las relaciones encontradas para los gastos directos e indirectos, primando en todos los casos la mayor participación de la población objetivo, donde los valores para 2016 fueron de niñez (primera infancia, niños y adolescentes) de \$67.292 millones, de Adultos \$28.389 millones y de adultos mayores $\$ 4.293$ millones. Luego en segundo lugar para niñez está mediadores con un valor de $\$ 21.367$ millones, pero para adultos y adultos mayores antes se ubica política pública con un valor de $\$ 9.039$ millones y $\$ 3.953$ millones respectivamente, quedando mediadores en tercer lugar para los adultos y en cuarto para los adultos mayores, con un valor que decrece a medida que aumenta la edad del grupo en cuestión. El tercer puesto para niñez lo ocupa política pública, con un valor de $\$ 11.513$ millones, y el tercero de adultos mayores corresponde a bien público por \$223 millones. Coincidiendo todos los grupos etarios en que el quinto puesto corresponde a instituciones, con valores bastante menores. 


\section{Gasto en Capital Mental por alcance del programa}

En \% del total

\begin{tabular}{|ccccc|}
\hline Alcance dol Programs & 2013 & 2014 & 2015 & 2016 \\
\hline Población Objetivo & $67,97 \%$ & $63,53 \%$ & $67,11 \%$ & $65,77 \%$ \\
\hline Institución & $0,43 \%$ & $0,63 \%$ & $0,53 \%$ & $0,35 \%$ \\
\hline Mediadores & $16,91 \%$ & $20,62 \%$ & $16,91 \%$ & $16,52 \%$ \\
\hline Bien Público & $1,27 \%$ & $1,08 \%$ & $0,74 \%$ & $1,24 \%$ \\
\hline Política Pública & $13,42 \%$ & $14,13 \%$ & $14,71 \%$ & $16,12 \%$ \\
\hline Total & $100 \%$ & $100 \%$ & $100 \%$ & $100 \%$ \\
\hline
\end{tabular}

Fuente: Elaboración propia en base a datos del Min. Economía PBA.

Realizando la comparación con respecto al Producto Bruto Geográfico (PBG) de la clasificación por alcance de cada programa del presupuesto, se encuentra que Población objetivo representa un 4,50\%, Mediadores 1,13\%, Política pública 1,10\%, Bien público 0,08\% e Instituciones 0,02\% del PBG para 2016. Donde en comparación con el año anterior, ha mermado la participación de los tres primeros y ha crecido la de los últimos dos grupos.

\section{Gasto en Capital Mental por Alcance de programa}

En \% del PBG

\begin{tabular}{|ccccc}
\hline Alcance del Programa & 2013 & 2014 & 2016 & 2016 \\
\hline Población Objetivo & $4,14 \%$ & $3,82 \%$ & $4,86 \%$ & $4,50 \%$ \\
\hline Institución & $0,03 \%$ & $0,04 \%$ & $0,04 \%$ & $0,02 \%$ \\
\hline Mediadores & $1,03 \%$ & $1,24 \%$ & $1,22 \%$ & $1,13 \%$ \\
\hline Bien Público & $0,08 \%$ & $0,07 \%$ & $0,05 \%$ & $0,08 \%$ \\
\hline Política Pública & $0,82 \%$ & $0,85 \%$ & $\mathbf{1 , 0 7 \%}$ & $\mathbf{1 , 1 0 \%}$ \\
\hline Total & $\mathbf{6 , 1 \%}$ & $\mathbf{6 , 0 \%}$ & $\mathbf{7 , 2 \%}$ & $\mathbf{6 , 8 \%}$ \\
\hline
\end{tabular}

Fuente: Elaboración propia en base a datos del Min. Economía PBA.

\section{Capital mental por área de impacto}

Se procedió a clasificar cada programa del presupuesto provincial de la serie 20132016 en función del área de bienestar y eje de intervención al cual contribuye:

- Alimentación saludable,

- Entorno saludable y estímulo cognitivo,

- Educación de calidad,

- Estímulo socioemocional. 
Analizando este criterio de clasificación, se observa que a lo largo de la serie el mayor peso del GCM se destina, preponderantemente, al área de educación de calidad $(75,1 \%)$; seguido por el gasto destinado a un entorno saludable y estimulo cognitivo $(16,7 \%)$. En tercer lugar, el gasto en alimentación saludable (5,3\%), quedando por último el gasto a estímulos socioemocionales (2,8\%). Lo que en valores corrientes para el año 2016 son $\$ 110.855$ millones, $\$ 28.519$ millones, $\$ 9.067$ millones y $\$ 3.572$ millones, respectivamente.

El área alimentación saludable manifiesta en 2016 un incremento de \$3.477 millones $(+61,3 \%)$ respecto del monto alcanzado en el año 2015 , muy por encima del aumento del gasto total (+28\%). Del mismo modo, el área entorno saludable y estímulo cognitivo experimenta en 2016 una suba interanual de 49\%, siendo con la anterior las áreas que ganan participación relativa dentro del total del GCM. Por su parte, educación de calidad crece en 2016 la suma de $\$ 20.540$ millones, casi un 23\% más que los $\$ 90.307$ millones erogados en 2015. El bloque que menor aumento recibió en 2016 fue el de estímulo socioemocional, con un aumento de tan solo \$233 millones, representando un incremento interanual del $7 \%$.

\section{Gasto en Capital Mental por Área de Impacto}

En porcentaje

\begin{tabular}{lcccc}
\multicolumn{1}{c}{ Impacto especifico } & 2013 & 2014 & 2015 & 2018 \\
\hline Alimentación saludable & $6 \%$ & $5 \%$ & $5 \%$ & $6 \%$ \\
Entorno saludable y estimulo cognitivo & $14 \%$ & $15 \%$ & $16 \%$ & $19 \%$ \\
Educación de calidad & $77 \%$ & $77 \%$ & $76 \%$ & $73 \%$ \\
Estímulo socioemocional & $3 \%$ & $3 \%$ & $3 \%$ & $2 \%$ \\
\hline \multicolumn{1}{c}{ Total } & $100 \%$ & $100 \%$ & $100 \%$ & $100 \%$ \\
\hline
\end{tabular}

Fuente: Elaboración propia en base a datos del Min. Economía PBA.

La participación de cada una de las áreas de impacto muestra un comportamiento estable, con variaciones no significativas. En los últimos dos años el área de entorno saludable y estímulo cognitivo fue la que gana más participación.

Se observa una tendencia creciente en todas las áreas, destacándose el mayor crecimiento en alimentación saludable y entorno saludable y estímulo cognitivo.

Analizado el gasto anual pueden apreciarse los siguientes gráficos, donde es posible observar como hecho estilizado que la mayor proporción de gasto en la provincia de 
Buenos Aires se destina a educación de calidad, seguido luego de una marcada diferencia por entorno saludable y estímulo cognitivo, alimentación saludable y, por último, por estímulo socioemocional.

Considerando a las áreas de impacto como porcentaje del Producto Bruto Geográfico de la Provincia de Buenos Aires (PBG) se evidencia que en el 2016 el GCM se encuentra en 6,8\%, valor por encima de la media de 6,5\% del PBG. La variación, en línea con el aumento nominal en millones de pesos corrientes, muestra una participación creciente en los cuatro grupos a lo largo de toda la serie. Hay una leve baja en la participación en educación de calidad y estímulo socioemocional en pos de un aumento en el gasto en entorno saludable y estímulo cognitivo.

\section{Gasto en Capital Mental por Área de Impacto}

En \% PBG

\begin{tabular}{lcccc}
\hline \multicolumn{1}{c}{ Impacto especifico } & 2013 & 2014 & 2015 & 2018 \\
\hline Alimentación saludable & $0,3 \%$ & $0,29 \%$ & $0,34 \%$ & $0,41 \%$ \\
Entorno saludable y estímulo cognitivo & $0,9 \%$ & $0,92 \%$ & $1,17 \%$ & $1,28 \%$ \\
Educación de calidad & $4,7 \%$ & $4,60 \%$ & $5,52 \%$ & $4,99 \%$ \\
Estímulo socioemocional & $0,2 \%$ & $0,20 \%$ & $0,20 \%$ & $0,16 \%$ \\
\hline \multicolumn{1}{c}{ Total } & $\mathbf{6 , 1 \%}$ & $\mathbf{6 , 0 \%}$ & $\mathbf{7 , 2 \%}$ & $\mathbf{6 , 8 \%}$ \\
\hline
\end{tabular}

Fuente: Elaboración propia en base a datos del Min. Economía PBA.

Se observa el GCM como porcentaje del GPT que en el 2016 se encuentra en $34,6 \%$, lo cual demuestra una caída con respecto a los años anteriores.

\section{Gasto en Capital Mental por Área de Impacto}

En $\%$ GPT

\begin{tabular}{lcccc}
\multicolumn{1}{c}{ Impacto especifico } & 2013 & 2014 & 2015 & 2016 \\
\hline Alimentación saludable & $2,1 \%$ & $\mathbf{1 , 7 2 \%}$ & $\mathbf{1 , 7 7 \%}$ & $2,07 \%$ \\
Entorno saludable y estímulo cognitivo & $5,4 \%$ & $5,47 \%$ & $6,03 \%$ & $6,50 \%$ \\
Educación de calidad & $29,0 \%$ & $27,44 \%$ & $28,41 \%$ & $25,25 \%$ \\
Estímulo socioemocional & $\mathbf{1 , 3 \%}$ & $\mathbf{1 , 2 2 \%}$ & $\mathbf{1 , 0 5 \%}$ & $0,81 \%$ \\
\hline \multicolumn{1}{c}{ Total } & $\mathbf{3 7 , 3 \%}$ & $\mathbf{3 5 , 8 \%}$ & $\mathbf{3 7 , 3 \%}$ & $\mathbf{3 4 , 6 \%}$ \\
\hline
\end{tabular}

Fuente: Elaboración propia en base a datos del Min. Economía PBA. 
Puntualmente el área de entorno saludable y estimulo cognitivo fue la única que presentó un incremento, la cual crece de 5,4\% en 2013 a 6,5\% en 2016. Las demás presentaron una caída comparando el total de los años.

\section{Gasto en Capital Mental por Área de Impacto}

En $\%$ GPS

\begin{tabular}{lcccc}
\multicolumn{1}{c}{ Impreto especifico } & 2013 & 2014 & 2015 & 2016 \\
\hline Alimentación saludable & $3,5 \%$ & $2,90 \%$ & $2,96 \%$ & $3,70 \%$ \\
Entomo saludable y estímulo cognitivo & $9,0 \%$ & $9,23 \%$ & $10,09 \%$ & $11,63 \%$ \\
Educación de calidad & $48,0 \%$ & $46,26 \%$ & $47,56 \%$ & $45,19 \%$ \\
Estímulo socioemocional & $2,1 \%$ & $2,05 \%$ & $1,76 \%$ & $1,46 \%$ \\
\hline \multicolumn{1}{c}{ Total } & $\mathbf{6 2 , 6 \%}$ & $\mathbf{6 0 , 4 \%}$ & $\mathbf{6 2 , 4 \%}$ & $\mathbf{6 2 , 0 \%}$ \\
\hline
\end{tabular}

Fuente: Elaboración propia en base a datos del Min. Economía PBA.

Se observa que hubo una variación relativamente constante con respecto al impacto en el GPS de las distintas áreas de impacto. Analizando cada área se encuentra que educación de calidad y estímulos socioemocional fueron las que sufrieron una leve caída en su participación. Sin embargo, las áreas de alimentación saludable y entorno saludable y estimulo cognitivo visualizaron un leve aumento de $0,2 \%$ y $2,6 \%$, respectivamente.

En el anexo, se detalla el presente análisis para cada uno de los grupos etarios, donde en términos generales se percibe para los de menor edad la clara importancia de las áreas de educación de calidad (50,5\%) y entorno saludable y estímulo cognitivo (46,3\%), luego para el grupo de niñez y adolescencia toma más importancia el área de educación de calidad (79\%), seguida por entorno saludable y estímulo cognitivo (14,5\%), manteniéndose para ambos grupos el área de alimentación saludable en tercer lugar de prioridad. En cuanto a los adultos, educación de calidad $(72,6 \%)$ y entorno saludable y estímulo cognitivo $(22,6 \%)$ son las principales, quedando en último lugar alimentación saludable. Por último, en lo referente a adultos mayores, las relaciones cambian, siendo la de mayor participación entorno saludable y estímulo cognitivo (50\%), seguido por alimentación saludable (37\%), estímulos socioemocional (9,7\%) y en último lugar, educación de calidad (3,3\%). 


\section{Conclusiones}

El capital mental constituye uno de los activos más promisorios para el desarrollo de una comunidad. Crecientemente más relevante que el capital físico, representa la llave para habilitar el acceso a la población activa a puestos de trabajo intelectualmente intensivos y mejor remunerados. La "economía del conocimiento" representa una oportunidad, pero también una amenaza. Millones de puestos de trabajo de baja calificación desaparecerán en los próximos años. Por ello, es central que se fomente una mayor conciencia entre las autoridades gubernamentales, la comunidad educativa y la Sociedad Civil acerca de la necesidad de formular políticas públicas de protección y promoción de la nutrición saludable y la estimulación cognitiva y emocional.

Los problemas de comportamiento que surgen en la infancia y siguen siendo significativos en la vida adulta pueden aumentar los costos, tanto del sistema de salud, de justicia como de los demás servicios sociales. Por ello, es que la intervención temprana está asociada a menores niveles de participación en actos de violencia futuros, mejoras en la productividad laboral, mayores ingresos económicos, menor tolerancia a la corrupción, menor mortalidad materno-infantil y mayor equidad de género, entre otros.

De este modo, es que para superar la pobreza, mejorar los resultados educativos e incrementar los niveles de productividad los gobiernos deben "comenzar por el principio" ofreciendo programas de calidad para la atención prenatal y la educación, servicios integrales de desarrollo de la primera infancia, apoyo y educación para padres, cuidado infantil y educación preescolar, y transiciones efectivas a la escuela primaria. Como afirmó Heckman, la inversión durante la primera infancia reduce déficits y fortalece la economía, construyendo así las bases para las habilidades cognitivas, motoras y conductuales que habilitan para el éxito en la escuela, la profesión y la vida en general.

Adicionalmente, los programas de intervención para la niñez proporcionan otros valiosos beneficios, entre ellos una mayor igualdad de oportunidades entre hombres y mujeres, mayores tasas de participación laboral femenina, menores tasas de embarazo adolescente no deseado y mejores condiciones de salubridad, en el mediano y largo plazo. Por lo tanto, empoderar a las familias y las comunidades para que puedan proveer de un entorno saludable para el crecimiento de sus hijos debe ser una prioridad. La vida en 
familia, los jardines maternales y los centros de salud de calidad son cruciales, ya que aportan el contexto apropiado para el desarrollo de habilidades físicas y motoras, de aprendizaje, de lenguaje y habilidades sociales y emocionales.

La inversión pública dirigida al capital mental podría así ser una herramienta más en pos de mejorar el bienestar de los habitantes. Dado, que las intervenciones que promueven el cuidado y desarrollo del capital mental y el bienestar a lo largo de la vida tienen un impacto profundo tanto a nivel individual como colectivo.

Un primer paso es la determinación de la línea de base, un diagnóstico que incluye la identificación de las iniciativas y programas oficiales que lo protegen y lo promueven y de los recursos que se destinan a financiarlos.

El examen exhaustivo de los presupuestos de la provincia entre los años 2013 y 2016, y la clasificación de los programas en función de sus áreas de impacto y alcance, permitió realizar la primera metodología a nivel mundial de medición de gasto en inversión en capital mental (GCM). Brindando la posibilidad incluso de medir y cuantificar lo que otros gobiernos destinan al capital mental de sus habitantes. Incluso resultaría interesante incorporar al análisis una visión de costo-beneficios de los frutos de los distintos programas que desarrollan los gobiernos para el desarrollo del capital mental. Pero dado el presupuesto de la Provincia de Buenos Aires, más precisamente su estructura programática, no es factible llevar adelante este desafío, quedando esta propuesta para cuando la información presupuestaria así lo permita.

Para 2016 en GCM alcanzó un valor de \$152.013 millones experimentando un incremento de $\$ 33.597$ millones respecto a 2015 (+28,4\%). Las mediciones arrojan que en promedio se invirtió un 6,5\% del Producto Bruto Geográfico (PBG). En 2016 el Estado provincial invirtió un 6,8\% del PBG, frente a 7,2\% en 2015, 6\% en 2014 y 6,1\% en 2013.

El GCM dimensionado con respecto al Gasto Público Total (GPT) y al Gasto Público Social (GPS) representó para 2016 un 34,6\% del GPT, y en cuanto al GPS, que se desprende de contemplar los gastos públicos inherentes exclusivamente a la finalidad de Servicios Sociales del Clasificador Presupuestario, el total de GCM fue del 62\% del GPS, donde el promedio de la serie 2013-2016 fue de 61,8\% del GPS.

En relación con el alcance de los programas que conforman GCM se observa que en promedio, alrededor del $68,6 \%$ del mismo es considerado gasto directo, mientras que el 
31,4\% restante es indirecto. Lo que implica, que el programa o proyecto está dirigido a la población objetivo o grupo biológico específico.

Siendo para toda la serie en general, y para cada año en particular, el área de alcance de los programas más predominante la de población objetivo, seguida por mediadores, política pública, bien público e instituciones, en el último lugar. Donde, en términos porcentuales, para 2016, población objetivo representó el 65,7\%, mediadores el 16,5\%, política pública el $16,1 \%$, bien público el $1,2 \%$ e instituciones el $0,35 \%$ del total de gastos en capital mental. Se observa un crecimiento en valores corrientes de las áreas de alcance de los programas presupuestarios con excepción de instituciones, que presenta una pequeña merma de $-15,7 \%$ con respecto a 2015 . El incremento para las demás áreas de alcance fue de $25,8 \%$ para población objetivo; de 25,4\% para mediadores; de 116,3\% para bien público; y, de 40,7\% para política pública.

A lo largo de la serie se observa que el mayor peso del GCM se destina preponderantemente al área de educación de calidad $(75,1 \%)$, seguido por el gasto al área de entorno saludable y estímulo cognitivo (16,7\%). Luego, gasto en alimentación saludable $(5,3 \%)$, y quedando por último el gasto a estímulos socioemocionales $(2,8 \%)$.

En 2016, la distribución del GCM por grupo etario arrojó que dos tercios era destinado a la niñez $(66,6 \%)$, un cuarto a adultos $(27,7 \%)$ y un $5,7 \%$ a adultos mayores. De esta forma, el gobierno provincial invirtió \$20.326 en el capital mental de cada niño bonaerense, $\$ 16.936$ por adulto bonaerense y \$3.289 por adulto mayor. Un patrón uniforme de la serie es la tendencia menguante del gasto con el avance del ciclo de vida. En términos del GPT y del GPS, representó un monto invertido en niñez del 23\% del GPT, y puede atribuirse a primera infancia el 5,7\% y a niñez y adolescencia el 17,4\% restante; en adultos 9,6\% del GPT; y en adultos mayores el 2\% del GPT. En cuanto al GPS, niñez representó el $41,2 \%$, el cual $10,6 \%$ corresponde a primera infancia y el 30,6\% a niñez y adolescencia; a adultos el $17,2 \%$ y a adultos mayores el 3,5\% del GPS.

Se destaca la participación del grupo etario niñez con el 4,5\% del producto de los bonaerenses en 2016. En cuanto al grupo etario de los adultos, el ratio alcanza en 2015 y 2016 un valor de 1,9\% del PBG con una tendencia ascendente respecto al inicio de la serie. Cuestión análoga sucede con el grupo de los adultos mayores que promedia una participación relativa de $0,35 \%$ en los años observados, con un comportamiento en alza. 


\section{Referencias}

Andlin-Sobocki P, Jönsson B, Wittchen HU, Olesen J (2005). Costofdisordersofthebrain in Europe. European Journal of neurology 12: 1-27.

Becker, G. S. (1962). Investment in human capital: A theoretical analysis. Journal of political economy, 70(5, Part 2), 9-49.

Beddington, J; Cooper, C; Field, J; Goswami, U; Huppertr, F; Jenkins, R; Jones, H; Kirkwood, T; Sahakian, B; Thomas, S (2008). The Mental Wealth of Nations, Nature.

Blackwell LS, Trzesniewski KH, Dweck CS (2007). Implicit theories of intelligence predict achievement across an adolescent transition: A longitudinal study and an intervention. Child development 78: 246-263.

Bleichrodt N, Born MP (1994). A meta-analysis of research on iodine and its relationship to cognitive development. The damaged brain of iodine deficiency, New York: Cognizant Communication: 195-200.

Bonari, D. (2009). Gasto Público Social dirigido a la Niñez en la Argentina 1995-2007. Dirección de Análisis de Gasto Público y Programas Sociales y UNICEF: Ciudad de Buenos Aires.

Bortis, H. (1999). Classical-Keynesian Political Economy and Humanist Economic Policy. Social and Political Sciences in the Commonwealth of Independent States, 61.

Capital FM Wellbeing Project (2008). Mental capital and wellbeing: making the most of ourselves in the 21 st century. London: The Stationary Office.

Carta de San José sobre los derechos de las personas mayores en América Latina y El Caribe, San José, Costa Rica, 2014.

Cesaratto, S. (2008). The Classical Surplus 'Approach and the Theory of the Welfare State and Public Pensions. ‘. Sraffa or An Alternative Economics, 93-113.

Díaz Langou, G; Repetto, F (2014). Juventudes y Políticas Públicas, CIPPEC.

Díaz-Orueta U, Buiza-Bueno C, Yanguas-Lezaun J (2010). Reserva cognitiva: evidencias, limitaciones y líneas de investigación futura. Revista Española de geriatría y Gerontologia 45: 150-155.

Duro, E (2012). Adolescencia y Políticas Públicas, UNICEF. 
Fernández, G (2017). Ergonomía: Condiciones y medio ambiente de trabajo. La prevención en medicina del trabajo como factor integrador, Microjuris.com.

Gobierno de la Provincia de Buenos Aires, Jefatura de Gabinete de Ministros, Unidad de Coordinación para el Desarrollo del Capital Mental (2017). Cuidado y Desarrollo del Capital Mental: Iniciativas en curso.

Gobierno de la Provincia de Buenos Aires, Ministerio de Coordinación y Gestión Pública, Unidad de Coordinación para el Desarrollo del Capital Mental (2016). Capital Mental: Qué es y cómo potenciar su desarrollo.

Hackman DA, Farah MJ, Meaney MJ (2010). Socioeconomic status and the brain: mechanistic insights from human and animal research. NaturereviewsNeuroscience.

Heckman J (2016). La inversión en el desarrollo durante la primera infancia: Reduce déficits y fortalece la economía. Heckman. The economics of human potential.

Izquierdo A, Pessino C, Vuletin G (2018). Mejor gasto para mejores vidas. Cómo América Latina y el Caribe puede hacer más con menos. BID.

Juárez-García A (2007). Factores psicosociales laborales relacionados con la tensión arterial y síntomas cardiovasculares en personal de enfermería en México. Salud pública de México 49: 109-117.

Koletzko B, Beyer J, Brands B, Demmelmair H, Grote V, et al. (2013). Early influences of nutrition on postnatal growth. Recent Advances in Growth Research: Nutritional, Molecular and Endocrine Perspectives: Karger Publishers. pp. 11-27.

Kurz, H. D., \& Salvadori, N. (2003). Theories of economic growth: old and new. The Theory of Economic Growth: A 'Classical'Perspective, Cheltenham, Edward Elgar.

Lazzarini, A. (2011). Revisiting the Cambridge capital theory controversies: a historical and analytical study. Pavia: Pavia University Press.

León-Cava N, Lutter C, Ross J, Martin L (2002). Cuantificación de los beneficios de la lactancia materna: reseña de la evidencia.

Mc Daid, D (2011). Investing in Mental Health and Well-Being: Findings from the DtaPrev Project, Oxford University Press.

Mongiovi, G. (1990). Notes on Say's law, classical economics and the theory of effective demand. Contributions to Political Economy, 9, 69. 
OCDE (2010). Sickness, Disability and Work: Breaking the Barriers. A Synthesis of Findings across OECD Countries.

Organización Internacional del Trabajo (2014). Promoción de la Salud y el Bienestar en el Trabajo, www.ilo.org.

Panico, C. (1988). Interest and Profit in the Theories of Value and Distribution. Springer.

Paolo C. Belli FB, \& Alexander Preker (2017). ¿Cuáles son los beneficios económicos de las inversiones en salud infantil? Organización Mundial de la Salud.

Parigi, F. (1974). Le imposte sui profitti nelle teorie della distribuzione basate sul concetto di sovrappiù. Studi economici, (2), 63-86.

Pivetti, M. (1985). On the Monetary Explanation of Distribution.

Pivetti, M. (1991). An essay on money and distribution. Macmillan.

Rozanes, M (2010). Capital Mental: Estrés en el Trabajo, El Economista, México.

Salud OMdl (2017). Crecimiento acelerado de la población adulta de 60 años y más de edad: Reto para la salud pública.

Salud OMdl (2017). La Salud Mental y los Adultos Mayores.

Salud OPdl (2017). Crecimiento acelerado de la población adulta de 60 años y más de edad: Reto para la salud pública.

Schultz, T. W. (1961). Investment in human capital. The American economic review, 51(1), 1-17.

Serrano, F. (1995). Long period effective demand and the Sraffian supermultiplier. Contributions to Political Economy, 14, 67.

Smith, A. (1794). La riqueza de las naciones (Vol. 1). Oficina de Viuda e Hijos de Santander. Valladolid 1794.

Solis M, Ciullo S, Vaughn S, Pyle N, Hassaram B, et al. (2012). Reading comprehension interventions for middle school students with learning disabilities: A synthesis of 30 years of research. Journal of learning disabilities 45: 327-340. 
Solow, R. M. (1956). A contribution to the theory of economic growth. The quarterly journal of economics, 70(1), 65-94.

Suhrcke M, Pillas D, Selai C (2008). Economic aspects of mental health in children and adolescents. Social cohesion for mental well-being among adolescents Copenhagen: WHO Regional Office for Europe.

Torrado Ramos, A; Sánchez Pérez, L; Somonte López, R; Cabrera Marsden, A; Henríquez Santos, P; Pérez, O (2014). Envejecimiento Poblacional: Una mirada desde los programas y políticas públicas de América Latina, Europa y Asia, Universidad de La Habana, Cuba.

U.K. Government Foresight Project, Office for Science: Mental Capital and Wellbeing: Final Project, 2008.

U.K. Government Foresight Project, Office for Science: Mental Capital and Wellbeing: Making the Most of Ourselves in the 21st Century, 2008.

U.K. Government Foresight Project, Office for Science: Mental Capital Through Life: Future Chllenges, 2008.

UNICEF (2009). Implementación a gran escala: El desarrollo de la primera infancia en América Latina.

Vegas, E; Santibáñez, L; Lora, E (2011). La Realidad Social, Los niños primero: Política Públicas para el desarrollo de la primera infancia, Instituto Interamericano para el Desarrollo Económico y Social (IDES), Banco Interamericano de Desarrollo (BID).

Verdoorn, J. P. (1949). On the factors determining the growth of labor productivity. Italian economic papers, 2, 59-68.

Viveros Madariaga, A (2001). Envejecimiento y vejez en América Latina y el Caribe: Políticas Públicas y las acciones de la sociedad, CEPAL.

Walras, L., \& Walras, L. (1987). Elementos de economía política pura: (o teoría de la riqueza social) (No. 330.1 WALe).

Weehuizen, R. M. (2008). Mental capital: the economic significance of mental health (Doctoral dissertation, Maastricht university). 


\section{Anexo}

Los siguientes cuadros han sido elaborados en base a la información brindada por la Dirección Provincial de Estudios Económicos del Ministerio de Economía de la provincia de Buenos Aires de los presupuestos ejecutados.

Gasto en Capital Mental por alcance del impacto

En millones de pesos corrientes y porcentaje

\begin{tabular}{|c|c|c|c|c|c|c|c|c|}
\hline \multicolumn{9}{|c|}{ Primera Infancia } \\
\hline \multirow[b]{2}{*}{ Clase } & \multicolumn{2}{|c|}{2013} & \multicolumn{2}{|c|}{2014} & \multicolumn{2}{|c|}{2015} & \multicolumn{2}{|c|}{2016} \\
\hline & $\begin{array}{l}\text { En mm des } \\
\text { corrientes }\end{array}$ & $\begin{array}{c}\text { En } \\
\text { porcentaje }\end{array}$ & $\begin{array}{l}\text { En min des } \\
\text { corrientes }\end{array}$ & $\begin{array}{c}\text { En } \\
\text { porcentaje }\end{array}$ & $\begin{array}{l}\text { En min des } \\
\text { corrientes }\end{array}$ & $\begin{array}{c}\text { En } \\
\text { porcentaje }\end{array}$ & $\begin{array}{l}\text { En mm des } \\
\text { corrientes }\end{array}$ & $\begin{array}{c}\text { En } \\
\text { porcentale }\end{array}$ \\
\hline Directo & 6.472 & $63,3 \%$ & 7.906 & $62,7 \%$ & 14.728 & $67,4 \%$ & 15.237 & $61,2 \%$ \\
\hline Indirecto & 3.756 & $36,7 \%$ & 4.700 & $37,3 \%$ & 7.139 & $32,6 \%$ & 9.641 & $38,8 \%$ \\
\hline Total & 10.228 & $100 \%$ & 12.606 & $100 \%$ & 21.867 & $100 \%$ & 24.878 & $100 \%$ \\
\hline
\end{tabular}

Gasto en Capital Mental por alcance del impacto en primera infancia En porcentaje

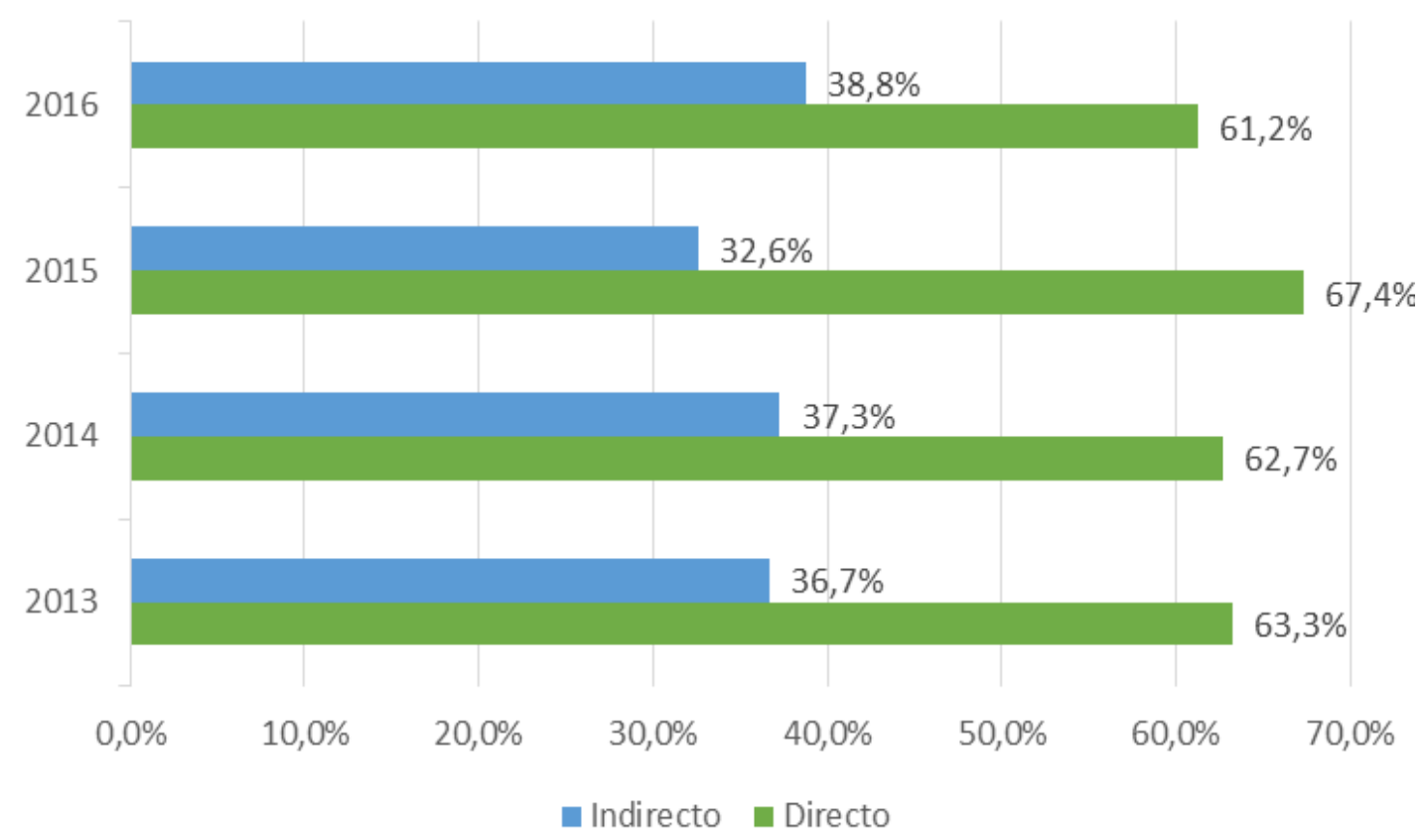


Gasto en Capital Mental por alcance del impacto

En millones de pesos corrientes

\begin{tabular}{|c|c|c|c|c|c|c|c|c|}
\hline \multicolumn{9}{|c|}{ Niñez y adolescencia } \\
\hline \multirow[b]{2}{*}{ Clase } & \multicolumn{2}{|c|}{2013} & \multicolumn{2}{|c|}{2014} & \multicolumn{2}{|c|}{2015} & \multicolumn{2}{|c|}{2016} \\
\hline & $\begin{array}{l}\text { En mm de S } \\
\text { corrientes }\end{array}$ & $\begin{array}{c}\text { En } \\
\text { porcentaje }\end{array}$ & $\begin{array}{l}\text { En mm de S } \\
\text { corrientes }\end{array}$ & $\begin{array}{c}\text { En } \\
\text { porcentaje }\end{array}$ & $\begin{array}{l}\text { En mm de S } \\
\text { corrientes }\end{array}$ & $\begin{array}{l}\text { En } \\
\text { porcentaje }\end{array}$ & $\begin{array}{l}\text { En mm de S } \\
\text { corrientes }\end{array}$ & $\begin{array}{c}\text { En } \\
\text { porcentaje }\end{array}$ \\
\hline Directo & 30.495 & $70,1 \%$ & 36.251 & $67,7 \%$ & 58.279 & $72,0 \%$ & 72.408 & $71,6 \%$ \\
\hline Indirecto & 12.999 & $29,9 \%$ & 17.289 & $32,3 \%$ & 22.719 & $28,0 \%$ & 28.759 & $28,4 \%$ \\
\hline Total & 43.494 & $100 \%$ & 53.540 & $100 \%$ & 80.998 & $100 \%$ & 101.167 & $100 \%$ \\
\hline
\end{tabular}

Gasto en Capital Mental por alcance del impacto en niñez y adolescencia En porcentaje

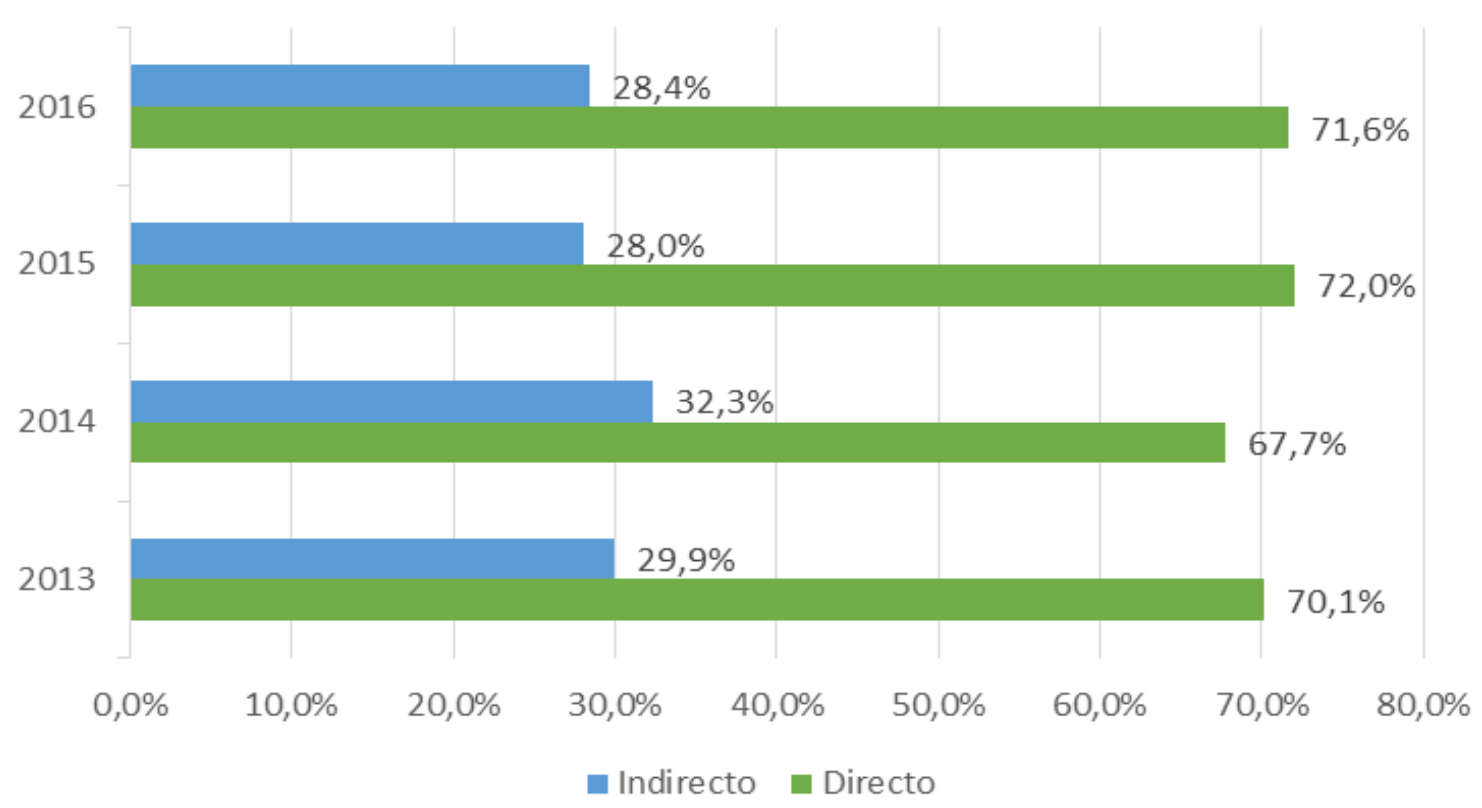

Gasto en Capital Mental por alcance del impacto

En millones de pesos corrientes

\section{Adultos}

\begin{tabular}{|c|c|c|c|c|c|c|c|c|}
\hline \multirow[b]{2}{*}{ Clase } & \multicolumn{2}{|c|}{2013} & \multicolumn{2}{|c|}{2014} & \multicolumn{2}{|c|}{2015} & \multicolumn{2}{|c|}{2016} \\
\hline & $\begin{array}{l}\text { En mm de } \mathrm{S} \\
\text { corrientes }\end{array}$ & En En & $\begin{array}{l}\text { En min de } \mathrm{S} \\
\text { corrientes }\end{array}$ & Eorcentale & $\begin{array}{l}\text { En min de } \mathrm{S} \\
\text { corrientes }\end{array}$ & Eorcentaje & $\begin{array}{l}\text { En mm des } \\
\text { corrientes }\end{array}$ & En En \\
\hline Directo & 8.153 & $64,0 \%$ & 12.933 & $66,9 \%$ & 21.868 & $69,0 \%$ & 28.389 & $67,3 \%$ \\
\hline Indirecto & 4.589 & $36,0 \%$ & 6.395 & $33,1 \%$ & 9.823 & $31,0 \%$ & 13.813 & $32,7 \%$ \\
\hline Total & 12.742 & $100 \%$ & 19.328 & $100 \%$ & 31.891 & $100 \%$ & 42.202 & $100 \%$ \\
\hline
\end{tabular}


Gasto en Capital Mental por alcance del impacto en adultos

En porcentaje

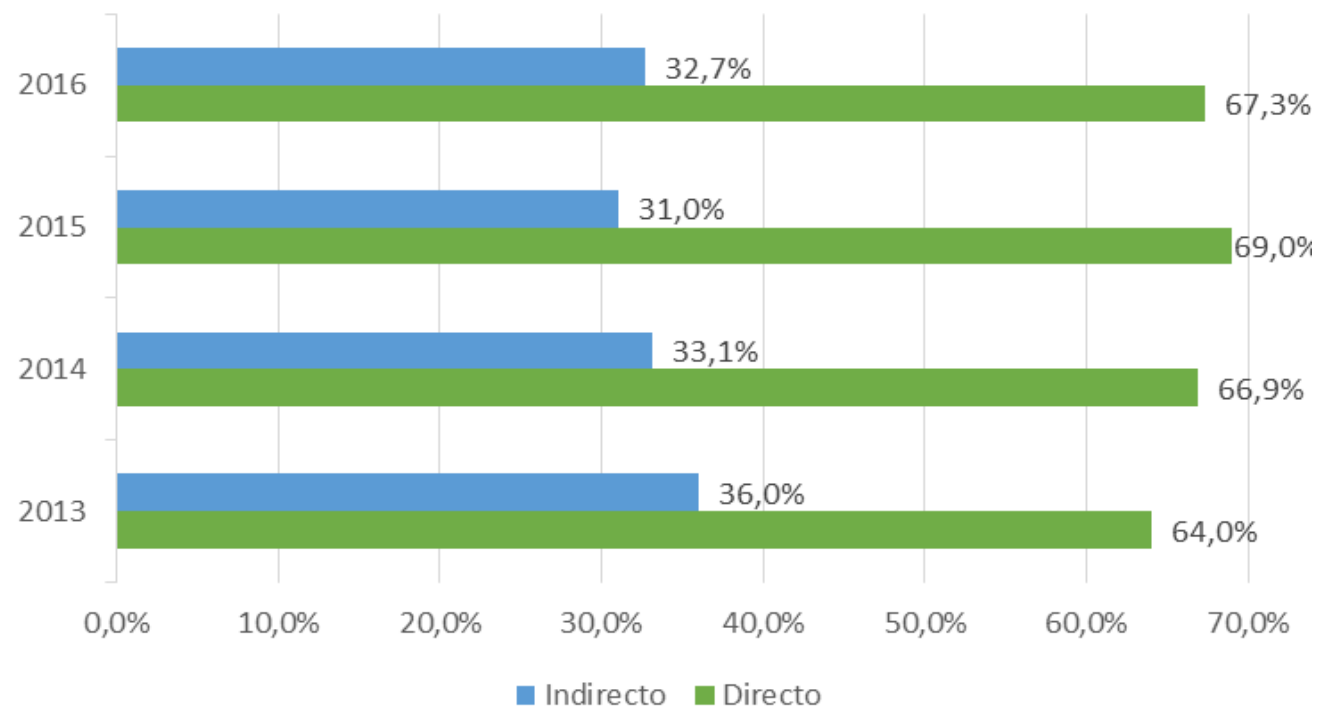

Gasto en Capital Mental por alcance del impacto

En millones de pesos corrientes

\begin{tabular}{|c|c|c|c|c|c|c|c|c|}
\hline \multicolumn{9}{|c|}{ Adultos mayores } \\
\hline \multirow[b]{2}{*}{ Clase } & \multicolumn{2}{|c|}{2013} & \multicolumn{2}{|c|}{2014} & \multicolumn{2}{|c|}{2015} & \multicolumn{2}{|c|}{2016} \\
\hline & $\begin{array}{l}\text { En mm de } \mathrm{S} \\
\text { corrientes }\end{array}$ & $\begin{array}{c}\text { En } \\
\text { porcentaje }\end{array}$ & $\begin{array}{l}\text { En mm de S } \\
\text { corrientes }\end{array}$ & $\begin{array}{c}\text { En } \\
\text { porcentaje }\end{array}$ & $\begin{array}{l}\text { En mm de S } \\
\text { corrientes }\end{array}$ & $\begin{array}{c}\text { En } \\
\text { porcentaje }\end{array}$ & $\begin{array}{l}\text { En mm de S } \\
\text { corrientes }\end{array}$ & $\begin{array}{l}\text { En } \\
\text { porcentaje }\end{array}$ \\
\hline Directo & 1.797 & $55,0 \%$ & 2.408 & $59,6 \%$ & 3.214 & $56,1 \%$ & 4.293 & $49,7 \%$ \\
\hline Indirecto & 1.472 & $45,0 \%$ & 1.631 & $40,4 \%$ & 2.515 & $43,9 \%$ & 4.352 & $50,3 \%$ \\
\hline Total & 3.269 & $100 \%$ & 4.039 & $100 \%$ & 5.728 & $100 \%$ & 8.644 & $100 \%$ \\
\hline
\end{tabular}

Gasto en Capital Mental por alcance del impacto en adultos mayores En porcentaje

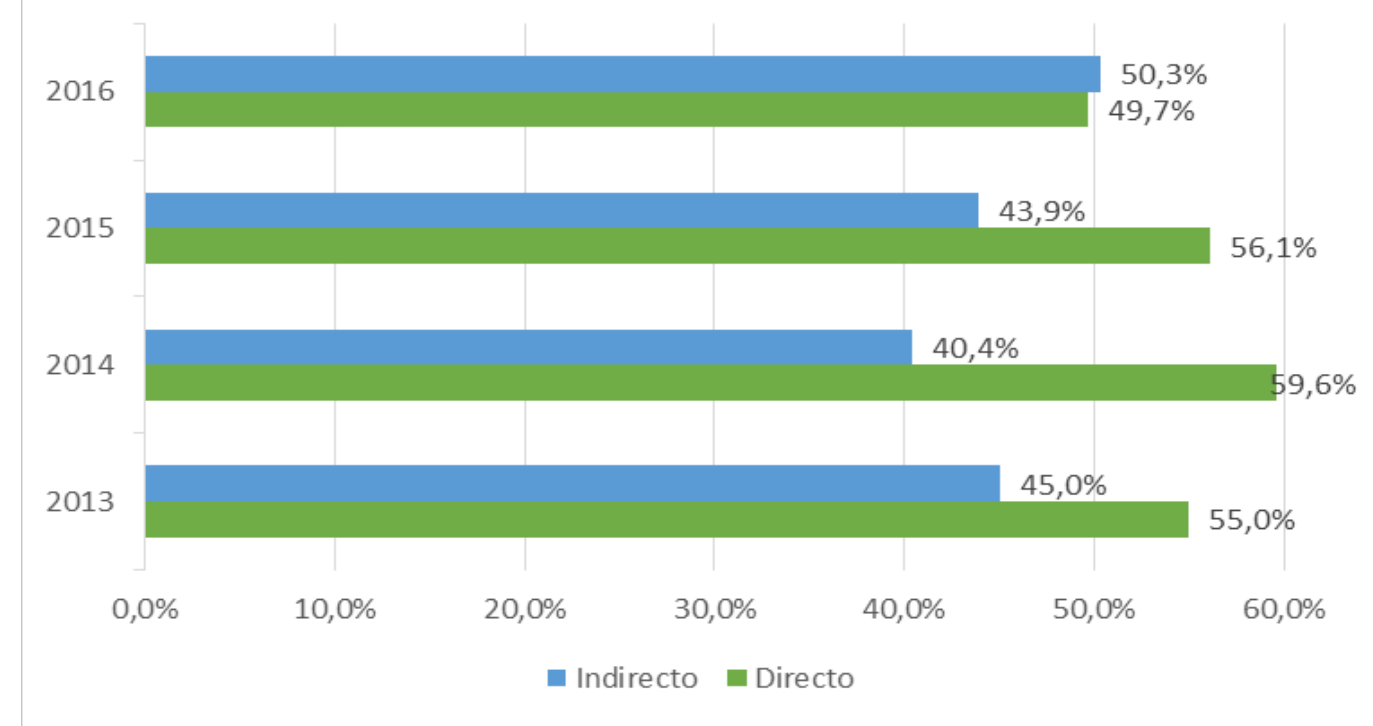


Gasto en Capital Mental por alcance de programa

En millones de pesos corrientes

\begin{tabular}{|c|c|c|c|c|}
\hline \multicolumn{5}{|c|}{ Primera infancia, Niñez y Adolescencia } \\
\hline Alcance del Programa & 2013 & 2014 & 2015 & 2016 \\
\hline Población Objetivo & 30.495 & 33.520 & 54.397 & 67.292 \\
\hline Institución & 76 & 106 & 143 & 141 \\
\hline Mediadores & 8.620 & 13.957 & 17.291 & 21.367 \\
\hline Bien Público & 398 & 489 & 539 & 855 \\
\hline Política Pública & 3.904 & 5.467 & 8.628 & 11.513 \\
\hline Total & 43.494 & 53.539 & 80.998 & 101.168 \\
\hline
\end{tabular}

\begin{tabular}{|crrrr|}
\hline \multicolumn{5}{c}{ Adultos } \\
Alcance del Programa & \multicolumn{1}{c}{ 2013 } & \multicolumn{1}{c}{ 2014 } & \multicolumn{1}{l}{ 2015 } & \multicolumn{1}{c|}{2018} \\
\hline Población Objetivo & 8.153 & 12.933 & 21.864 & 28.389 \\
\hline Institución & 136 & 320 & 401 & 378 \\
\hline Mediadores & 1.415 & 1.869 & 2.691 & 3.590 \\
\hline Bien Público & 283 & 250 & 282 & 806 \\
\hline Política Pública & 2.754 & 3.956 & 6.453 & 9.039 \\
\hline Total & $\mathbf{1 2 . 7 4 2}$ & $\mathbf{1 9 . 3 2 7}$ & $\mathbf{3 1 . 6 9 1}$ & $\mathbf{4 2 . 2 0 1}$ \\
\hline
\end{tabular}

\section{Adultos Mayores}

\begin{tabular}{|crrrrr|}
\hline Aloance del Programa & \multicolumn{2}{l}{2013} & 2018 \\
\hline Población Objetivo & 1.797 & 2.408 & 3.212 & 4.293 \\
\hline Institución & 43 & 58 & 79 & 19 \\
\hline Mediadores & 27 & 35 & 44 & 156 \\
\hline Bien Público & 74 & 94 & 51 & 223 \\
\hline Política Pública & 1.327 & 1.444 & 2.343 & 3.953 \\
\hline Total & $\mathbf{3 . 2 6 9}$ & $\mathbf{4 . 0 3 9}$ & $\mathbf{5 . 7 2 8}$ & $\mathbf{8 . 6 4 4}$ \\
\hline
\end{tabular}


Gasto en Capital Mental por impacto específico primera infancia En millones de pesos corrientes

\begin{tabular}{lrrrr}
\multicolumn{1}{c}{ Impacto especifico } & \multicolumn{1}{l}{2013} & \multicolumn{2}{l}{2015} \\
\hline Alimentación saludable & 1.176 & 382 & 497 & 565 \\
Entorno saludable y estímulo cognitivo & 3.772 & 5.279 & 8.357 & 11.511 \\
Educación de calidad & 4.900 & 6.715 & 12.686 & 12.565 \\
Estímulo socioemocional & 380 & 230 & 327 & 238 \\
\hline \multicolumn{1}{c}{ Total } & $\mathbf{1 0 . 2 2 9}$ & $\mathbf{1 2 . 6 0 6}$ & $\mathbf{2 1 . 8 6 6}$ & $\mathbf{2 4 . 8 7 9}$ \\
\hline
\end{tabular}

Gasto en Capital Mental por impacto específico primera infancia En $\%$ del total del gasto en primera infancia

\begin{tabular}{lcccc}
\multicolumn{1}{c}{ Impacto especifico } & 2013 & 2014 & 2015 & 2018 \\
\hline Alimentación saludable & $11,50 \%$ & $3,03 \%$ & $2,27 \%$ & $2,27 \%$ \\
Entorno saludable y estimulo cognitivo & $36,88 \%$ & $41,88 \%$ & $38,22 \%$ & $46,27 \%$ \\
Educación de calidad & $47,91 \%$ & $53,26 \%$ & $58,02 \%$ & $50,50 \%$ \\
Estímulo socioemocional & $3,72 \%$ & $1,83 \%$ & $1,49 \%$ & $0,95 \%$ \\
\hline \multicolumn{1}{c}{ Total } & $100 \%$ & $100 \%$ & $100 \%$ & $100 \%$ \\
\hline
\end{tabular}

Gasto en Capital Mental por impacto específico niñez y adolescencia En millones de pesos

\begin{tabular}{lrrrr}
\multicolumn{1}{c}{ Impacto espacifico } & \multicolumn{1}{c}{2013} & \multicolumn{1}{c}{2015} & \multicolumn{1}{c}{2016} \\
\hline Alimentación saludable & 1.950 & 1.902 & 3.155 & 5.543 \\
Entorno saludable y estímulo cognitivo & 4.519 & 6.612 & 10.660 & 14.709 \\
Educación de calidad & 36.032 & 43.855 & 65.677 & 79.897 \\
Estímulo socioemocional & 993 & 1.170 & 1.505 & 1.019 \\
\hline \multicolumn{1}{c}{ Total } & $\mathbf{4 3 . 4 9 4}$ & $\mathbf{5 3 . 5 3 9}$ & $\mathbf{8 0 . 9 9 8}$ & $\mathbf{1 0 1 . 1 6 8}$
\end{tabular}

Gasto en Capital Mental por impacto específico niñez y adolescencia En \% del total del gasto en niñez y adolescencia

\begin{tabular}{|ccccc}
\multicolumn{1}{c}{ In } & 2013 & 2014 & 2015 & 2016 \\
\hline Alimentación saludable & $4,48 \%$ & $3,55 \%$ & $3,90 \%$ & $5,48 \%$ \\
Entorno saludable y estímulo cognitivo & $10,39 \%$ & $12,35 \%$ & $13,16 \%$ & $14,54 \%$ \\
Educación de calidad & $82,84 \%$ & $81,91 \%$ & $81,09 \%$ & $78,97 \%$ \\
Estímulo socioemocional & $2,28 \%$ & $2,19 \%$ & $1,86 \%$ & $1,01 \%$ \\
\hline \multicolumn{1}{c}{ Total } & $100 \%$ & $100 \%$ & $100 \%$ & $100 \%$ \\
\hline
\end{tabular}


Gasto en Capital Mental por impacto específico adultos

En millones de pesos corrientes

\begin{tabular}{lrrrrr}
\hline \multicolumn{1}{c}{ Impreto especifico } & \multicolumn{2}{c}{2013} & 2015 & 2016 \\
\hline Alimentación saludable & 10 & 12 & 17 & 332 \\
Entorno saludable y estímulo cognitivo & 2.535 & 3.431 & 5.955 & 9.519 \\
Educación de calidad & 9.459 & 14.841 & 24.337 & 30.636 \\
Estímulo socioemocional & 738 & 1.044 & 1.382 & 1.714 \\
\hline \multicolumn{1}{c}{ Total } & $\mathbf{1 2 . 7 4 2}$ & $\mathbf{1 9 . 3 2 7}$ & $\mathbf{3 1 . 6 9 1}$ & $\mathbf{4 2 . 2 0 1}$ \\
\hline
\end{tabular}

Gasto en Capital Mental por impacto específico adultos

En \% del gasto total en adultos

\begin{tabular}{lcccc}
\multicolumn{1}{c}{ Impacto espacfico } & 2013 & 2014 & 2015 & 2016 \\
\hline Alimentación saludable & $0,08 \%$ & $0,06 \%$ & $0,05 \%$ & $0,79 \%$ \\
Entorno saludable y estímulo cognitivo & $19,89 \%$ & $17,75 \%$ & $18,79 \%$ & $22,56 \%$ \\
Educación de calidad & $74,23 \%$ & $76,79 \%$ & $76,80 \%$ & $72,60 \%$ \\
Estímulo socioemocional & $5,79 \%$ & $5,40 \%$ & $4,36 \%$ & $4,06 \%$ \\
\hline \multicolumn{1}{c}{ Total } & $100 \%$ & $100 \%$ & $100 \%$ & $100 \%$ \\
\hline
\end{tabular}

Gasto en Capital Mental por impacto específico adultos mayores

En millones de pesos corrientes

\begin{tabular}{lrrrr}
\multicolumn{1}{c}{ Impacto especifico } & \multicolumn{1}{c}{2013} & 2015 & \multicolumn{2}{c}{2016} \\
\hline Alimentación saludable & 1.333 & 1.780 & 2.448 & 3.193 \\
Entorno saludable y estímulo cognitivo & 1.511 & 1.696 & 2.535 & 4.291 \\
Educación de calidad & 127 & 168 & 293 & 322 \\
Estímulo socioemocional & 299 & 395 & 452 & 839 \\
\hline \multicolumn{1}{c}{ Total } & $\mathbf{3 . 2 6 9}$ & $\mathbf{4 . 0 3 9}$ & $\mathbf{5 . 7 2 8}$ & $\mathbf{8 . 6 4 4}$ \\
\hline
\end{tabular}

Gasto en Capital Mental por impacto específico adultos mayores

En \% del gasto total en adultos mayores

\begin{tabular}{lcccc}
\multicolumn{1}{c}{ Impacto especfifico } & 2013 & 2014 & 2015 & 2016 \\
\hline Alimentación saludable & $40,76 \%$ & $44,07 \%$ & $42,74 \%$ & $36,93 \%$ \\
Entorno saludable y estímulo cognitivo & $46,21 \%$ & $41,98 \%$ & $44,26 \%$ & $49,64 \%$ \\
Educación de calidad & $3,89 \%$ & $4,17 \%$ & $5,11 \%$ & $3,73 \%$ \\
Estímulo socioemocional & $9,15 \%$ & $9,78 \%$ & $7,89 \%$ & $9,70 \%$ \\
\hline \multicolumn{1}{c}{ Total } & $100 \%$ & $100 \%$ & $100 \%$ & $100 \%$ \\
\hline
\end{tabular}

